\title{
MARKETING: UN PARADIGMA BALBUCEANDO EN UN CAPITALISMO MUTANDO1
}

\section{Jorge Enrique Garcés Cano}

\section{LAS CUATRO PES DEL MERCADEO:IIICIO DEL ÉNFASIS OPERATIVO}

La relevancia otorgada a los temas comerciales-empresariales viene dada por el avance y desarrollo del capitalismo; así como el afianzamiento de la empresa moderna. Los análisis en economía, más exactamente en microeconomía, que pretendían entender el comportamiento de empresas y consumidores, no abordaban

\section{RESUMEN}

El Marketing es un paradigma en pleno proceso de desarrollo. Cada vez se identifican más los elementos que lo acercan a la ciencia de aquellos que lo separan, y le han dado énfasis a planteamientos bastante más cercanos a la metafísica, lo esotérico o cualquier enfoque anticientífico. Con tal visión, una ruta que nos permita establecer los conceptos y la relación entre lo estratégico y lo táctico (operativo), entre sus procesos (identificación, creación, comunicación y entrega de valor -de cambio y de uso-) y sus funciones, y entre sus elementos (componentes) y sus instrumentos (herramientas), es sin lugar a dudas el primer paso para lograr fundamentarlo como ciencia (social y aplicada -léase, tecnología). Adicionalmente, la planeación estratégica de mercadeo toma mayor relevancia en un mundo donde los llamados servicios (o productos intangibles) ganan cada vez más peso en el contexto económico (dentro o fuera del modo de producción capitalista). Sea en escenarios de comercialización de tangibles o de intangibles, la relación dialéctica entre estrategia y táctica no cambia, aunque sí lo hagan las particularidades en el uso operacional de las diferentes variables de la "mezcla de mercadeo". Este es otro tema importante para tener presente.

\section{PALABRAS CLAVE}

Capitalismo, economía, marketing, mercadeo, mercadotecnia, comercialización, sistémica, dinámica, funcional, holística, mercado, oferta, demanda, necesidades, satis- factores, valor de uso, valor de cambio, estrategia, táctica, enfoque, objetivos, crecimiento, posicionamiento, competitividad, segmentación, producto, publicidad, promoción, ventas, técnica, tecnología y ciencia.

\section{ABSTRACT}

Marketing is a paradigm in full process of development. Increasingly the elements that put it close to the science from those that put it far are identified and have made emphasis on ideologies closer to the metaphysics, the esoteric or any other scientific approach. With such a vision, a route that enables us to establish the concepts and the relation between the strategic and the tactical (operating), between its processes (identification, creation, communication and value commitment - from change and use -) and its functions, and between its elements (parts) and its instruments (tools), is without doubt the first step to support it as a science (social and applied - reading it, technology). In addition, the marketing strategic planning becomes more outstanding in a world where the called services (or intangible products) gain more weight in the economic context (inside or outside the capitalist production mode). Whether it is in sceneries of tangible or intangible commercialization, the dialectic relationship between strategy and tactics doesn't change, even it does the particularities in the operating use of the different variables of "marketing mix". This is another important issue to keep in mind.

1. El presente trabajo fue desarrollado en el marco de Expoacademia 2003, de la Universidad Konrad Lorenz, Bogotá, octubre 14 de 2003. 
de manera detallada algunos aspectos del proceso comercial. Este distanciamiento entre los modelos económicos predominantes (fundamentalmente, las teorías clásica y neoclásica) y la actividad empresarial real de comienzos del siglo $\mathrm{XX}$, con sus necesidades y objetivos comerciales a corto plazo, conllevó al surgimiento del marketing como un cuerpo teórico aparte de la economía. Antes de ello era posible encontrar documentos y escritos sobre temas muy particulares: las ventas (centrados en el "espíritu y la fuerza del vendedor"); y la llamada "propaganda", punto de origen de lo que hoy conocemos como publicidad.

Ya para 1910, R. S. Butler desarrolló e impartió un curso de métodos de marketing en la Universidad de Wisconsin; y en 1911 aparecieron en los EEUU los dos primeros centros de investigación comercial. Sin embargo, se acepta el hecho histórico de que durante los primeros cincuenta años del pasado siglo no se hizo énfasis en atender posibles "necesidades cambiantes" de los consumidores; de por sí los "gustos" -una variable de la ecuación de demanda, que para la teoría neoclásica está “dada o es constante a largo plazo"-, no estaba en el centro de atención de la actividad empresarial. Parecía que la llamada "Ley de Say"2 operaba aún bajo

\section{RESEÑA DE AUTOR}

Jorge Enrique Garcés Cano, economista y Magíster en Economía, de la Universidad Nacional de Colombia; catedrático, asesor y consultor en temas de mercadeo, ventas y servicio al cliente, ha sido gerente de mercadeo en: EPM; Gas Natural S.A.; Colfondos, Pensiones y Cesantías; Banco Santander e Invercrédito S.A.; y director nacional de investigación de mercados en la aseguradora Colseguros S.A. amplios márgenes de "perfección” y por lo tanto, podríamos indicar que el marketing, como un cuerpo de conocimiento aparte de la teoría económica, iniciaría con un enfoque claramente produccionista y ofertista. De esa manera, no existen referencias importantes de la época, que indiquen algún avance o desarrollo del marketing como ciencia pues no era necesario.

Paradójicamente, en esos primeros años se desarrolla la investigación de mercados, como un intento de entender mejor los elementos de la demanda, a través de un formato que se extendería rápidamente por los EEUU en la segunda posguerra: las encuestas a los consumidores. Este intento por conocer más acerca del comportamiento de los consumidores se vería reforzado por el desarrollo de la psicología y la sociología; e igualmente, por la utilización de la estadística aplicada a las ciencias sociales.

Algunos autores -entre ellos P. Kotlerafirman, que el concepto de las cuatro pes fue inicialmente acuñado por E. Jerome McCarthy en 1960; sin embargo, a mediados de los 50 el profesor Neil H. Borden, de la Universidad de Harvard, se había referido al tema de la "mezcla de mercadeo", tratando de identificar y clasificar aquellos elementos que deberían componerla ${ }^{3}$.

Igualmente, se ha logrado establecer que para la misma época, en Europa, la llamada Escuela de Copenhague había llegado a una definición bastante cercana a las cuatro pes, utilizando los elementos de la Teoría de los Parámetros que en los años 30 habían desarrollado Von Stackelberg, Arne Rasmussen y Gosta Mickwitz, quienes estaban mucho

2. Jean Baptiste Say (1767-1832), "Ley de los mercados" o "Ley de la oferta y la demanda", según la cual, "toda oferta crea su propia demanda".

3. El trabajo de Borden incluía originalmente doce elementos, que fueron reducidos hasta condensarlos en las que hoy se conocen como las cuatro pes. 
más interesados en medir las elasticidades de la demanda y a través de ellas, identificar las diferentes fases de lo que hoy se denomina "el ciclo de vida de los productos".

Sea como fuere, se encuentran allí los orígenes de éste planteamiento operativo que durante casi medio siglo, desde la publicación del trabajo de McCarthy en 19604 ha preocupado por los temas operativos del proceso de mercadeo; de hecho, no es un evento aislado que el Diccionario de la Real Academia de la Lengua Española defina el mercadeo como una "actividad comercial" que describe el "conjunto de operaciones por las que ha de pasar una mercancía (léase, producto), desde el productor hasta el consumidor”. Y claro, entendido así, marketing, comercialización o mercadotecnia, que son tácitamente lo mismo, en esta concepción nos llevaría a hablar de una técnica, sofisticada o no, para lograr a través de algunas acciones (tácticas) que "la oferta" logre acercar (léase, deshacerse de...) sus productos a "la demanda".

El planteamiento, sea o no original de McCarthy, denominado las "cuatro pes", definía la necesidad de agrupar unas variables bajo la discrecionalidad empresarial, en bloques cuya naturaleza y funcionamiento permitieran ser estudiadas y tra- bajadas conjuntamente. En la tradición norteamericana, estos grupos de variables fueron definidos como:

- "PRODUCT", entendido en español como producto en cuanto a sus características técnicas, no como propuesta de valor para el consumidor.

- "PRICE", entendido como precio, léase bien, precio; no valor de cambio; mucho menos, valor de uso.

- "PLACE", entendido como distribución (no como plaza).

- "PROMOTION", entendido como promover o promocionar (no como promoción incentivo adicional) ${ }^{5}$.

Sería P. Kotler quien daría a conocer y difundir las ideas de McCarthy, e igualmente, quien afianzaría dos elementos opuestos de este enfoque:

1. Por una lado, el mercadeo como un cuerpo teórico que trata de explicar procesos que la economía no había logrado abordar por sí misma; y que como ciencia aplicada -o sea, tecnología, con origen en su ciencia básica-, venía utilizando elementos de administración y de psicología.

2. Por otro lado, una descripción del proceso de mercadeo sin definir ni establecer cuáles serían las variables dependientes

4. E. Jerome McCarthy. Basic Marketing: A Managerial Approach, Australia: McGraw-Hill, 1960.

5. En sentido estricto, "promoción" es literalmente un conjunto de acciones de apoyo al producto, diseñadas con el objetivo de "reactivar o crear una demanda adicional a la existente en el mercado"; y aunque se acepta que tradicionalmente el mecanismo utilizado por las empresas afecta directamente el precio, la mercadotecnia recomienda utilizar elementos indirectos (incentivos) cuya asociación al producto genera "mayor valor" (o valor agregado) para el consumidor (regalos, concursos, descuentos a clientes especiales, etc.). En tanto que la "promotion" a la que se refería McCarthy, es lo que los americanos entienden como promoción de ventas; o sea, un conjunto de actividades y elementos dirigidos a informar a los posibles consumidores de un producto sobre su existencia (promoviéndolos o promocionándolos); es decir, utilizando los elementos de la llamada comunicación persuasiva. Ya sería Kotler quien terminaría fusionando los dos temas, al definir esta actividad comunicativa como el papel central de las fuerzas de ventas, sumada al desarrollo de incentivos para los vendedores (presión por el lado de la oferta) y al desarrollo de incentivos para los consumidores (presión por el lado de la demanda); como si la naturaleza de estas tres variables les permitiera ser agrupadas, para su observación y medición. 
del modelo de marketing; es decir, aquellas por las cuales responderán las variables independientes ${ }^{6}$ : La mezcla de mercadeo; las tácticas, o sea, el marketing operativo, al que daría la mayor de las relevancias (posiblemente sin proponérselo).

Este hecho marcará el inicio de un proceso de más de cuarenta años, que aún hoy persiste: una enseñanza académica, una asesoría y consultoría de mercadeo, y una aplicación empresarial, centradas y enfocadas en los aspectos de la mezcla de mercadeo; es decir, en la capacidad de operar, casi siempre de manera intuitiva, las mal llamadas "Pes de Kotler".

Existe, sin embargo, cierto consenso de que al tratarse de una materia de muy reciente desarrollo científico (¿estado precientífico?), no ha existido entre los diferentes y crecientemente numerosos autores sobre mercadeo, un acuerdo acerca del significado y alcance de su definición; así como sobre su objeto de estudio y en función de ello, sus contenidos, sus procesos y su método:

\section{Para la Amercian Marketing} Association, se trataría de "el resultado de la actividad empresarial que dirige el flujo de bienes y servicios desde el productor hacia el consumidor o usuario". O sea, un aspecto centrado en el problema de la distribución física de los productos.
2. Para la Universidad de Ohio, 1965 , era "el proceso por el que una sociedad anticipa, aplaza o satisface la estructura de la demanda de bienes y servicios económicos, mediante la concepción, promoción, intercambio y distribución física de bienes y servicios". O sea, una suma de las actividades que adelantan productores y comercializadores para colocar su producto en el mercado. Es evidente que "un sistema" no puede ser entendido simplemente como la sumatoria de sus partes.

3. Para Peter Drucker, y tal vez es uno de los pioneros en el planteamiento (1954), Marketing es, junto con innovación, "la única función de una empresa”. Este es un enfoque administrativo que define la filosofía de negocios con la que sus accionistas deciden participar en el juego competitivo. Nótese que el planteamiento de fondo es fundamental, o sea, el problema filosófico que debería orientar la actividad empresarial, el encajonamiento en el tema funcional le quita peso al desarrollo del marketing como ciencia; es decir, su rol sistémico y su visión dinámica, que no tienen nada que ver con la casuística empresarial. De hecho, sólo cuando el marketing sea visto, enseñado y trabajado a través de los planteamientos de la ciencia, será posible eliminar el alto grado de subjetividad, discrecionalidad, manejo intuitivo y emocional ${ }^{7}$,

6. Resulta paradógico que ya para 1969 George Schwartz describía la necesidad de construir una teoría del mercadeo (marketing) que fuera realmente útil para el contro comercial: "La demostración de la existencia de relaciones causales entre variables dependientes e independientes predispone a los ejecutivos comerciales a realizar cambios en las variables dependientes actuando sobre una o más variables independientes, por ejemplo a influir en el aumento de las ventas (variable dependiente) actuando sobre todo el complejo comercial (variables independientes)". George Schwartz, La Teoría del Marketing, Barcelona; Ed. Labor S.A., 1969, p.162.

7. Este es precisamente el foco del trabajo desarrollado recientemente por Clancy y Krieg, en el año 2000, quienes con alguna evidencia estadística y una excelente argumentación, demuestran cómo aún en el llamado "mundo desarrollado" (los EEUU como país “ejemplo”), las decisiones empresariales y de negocios, con los temas comerciales (o de mercadeo) en su centro, siguen siendo tomadas con altas dosis de intuición; al vaivén de las coyunturas emocionales de sus "líderes" y la influencia que la testosterona puede ejercer en ellas. El resultado: un Marketing centrado en la intuición, que no ha permitido sentar las bases de sus procesos, desde la ciencia. Kevin J. Clancy y Peter C. Krieg, "Counter- Intuitive Marketing: Achive Great Results using Uncommon Sense", The Free Press, New York, 2000. 
con el que suelen atenderse los temas comerciales (y empresariales, en general).

4. Para Kotler, es una "ciencia aplicada" que se basa en los procesos de intercambio entre oferentes y demandantes, cuyo estudio corre a cargo de una teoría económica asumida como "una ciencia de la escasez". Una definición solo aceptada por una de las varias escuelas del pensamiento económico: la Teoría Neoclásica. Esta visión, a pesar de la insistencia del mismo Kotler, lo alejará de una concepción centrada en el hecho de que su ciencia básica u origen, la economía, es esencialmente una ciencia social.

\section{LOS DOS FACTORES DEFREY:UN INTENTO DE AGRUPACIÓN DIFERENTE}

En 1961 Albert W. Frey ${ }^{8}$ propuso igualmente una clasificación de las variables que tienen influencia en los procesos de mercadeo, entendiendo la necesidad de agruparlas en dos “factores", que paradójicamente contemplan un concepto de producto global mucho más completo que el planteado por Kotler, al incluirle el precio y al prestar especial atención al tema del servicio -no entendido simplemente como "los servicios” de atención que brinda el personal que asiste clientes-, que además, separa adecuadamente el concepto de fuerzas de ventas como canal de comercialización, del papel de la comunicación del producto o sea, propaganda; entendiendo que los dos aspectos del manejo de canales: comercialización o ventas y distribución física, aunque sean variables separadas, deben formar parte del mismo grupo o conglomerado que podríamos llamarlas, en un modelo de la ciencia: un factor estadístico.

Pero que lamentablemente, al igual que sus contemporáneos, sólo se remitirá a identificar los aspectos operativos del proceso de mercadeo y prestar especial atención a su implementación, como si ellos fueran la parte esencial de la estrategia como tal:

- Lo ofrecido: un producto, un empaque, una marca, un precio y un servicio.

- Los métodos y herramientas para poder ofrecer: los canales de distribución, las ventas personales, la propaganda, la promoción de ventas y la publicidad.

P. Kotler tomará de aquí algunas ideas, pero dejará de lado el énfasis dado por Frey al tema del servicio como variable de la mezcla de mercadeo, al pensar que este era un aspecto que solo se evidenciaba y tomaba relevancia en la comercialización de intangibles. Aspecto que sólo logrará ser revivido en los 80 , a partir de las experiencias de negocios y las ideas de empresarios como Jan Carlson; lamentablemente, dando inicio a otra oleada de "modas empresariales y de marketing" y no a un intento serio de vincularlo como una más de las variables fundamentales de un modelo de mercadeo.

\section{LOS TRES FACTORES DE LAZER Y KELLEY:MÁS ÉNFASIS EN LO OPERACIONAL}

Un año después, en 1962 William Lazer y Eugene J. Kelly ${ }^{9}$, propusieron su organiza-

8. Albert W. Frey, Advertising, Nueva York: Ronald Press, 1961. $3^{\text {a ed. }}$

9. William Lazer y Eugene J. Kelly, Managerial Marketing: Perspectives and Viewpoints, edición revisada, R. D. Irwin, 1962. 
Kotler y Zaltman involucraron un concepto económico-social en los temas de mercadeo, al definirlo como "el diseño, implementación $y$ control de programas calculados para influir la aceptabilidad de ideas sociales, incluyendo consideraciones de planificación del producto, precio, comunicación y distribución". ción en tres "factores", que sólo difieren del planteamiento de Frey en que acentúan en el tercer grupo de variables, en el tema de la comunicación; es decir, donde la "promocion" (léase, promover o promocionar un producto), aparece por primera vez como una parte de algo mucho más general (comunicar).

Sin embargo, vuelve a quedar opacado el problema de servir a los clientes; y queda ratificada la idea de que estas "variables" y los "factores" en que se agrupan, aunque se llamen así, no se conceptúan de esta manera con el fin de establecer un modelo matemático y estadístico que los relacione con otras variables, las realmente estratégicas, a las cuales deben "rendir explicación"; es decir, poder definir las unas, en función de las otras y así, construir modelos con alguna capacidad predictiva. Estos últimos elementos se reproducirán en el esquema de Kotler, no digamos, modelo, y en todas las "modas del mercadeo" que comenzarán a proliferar desde comienzos de los 80 .

Los factores de Lazer y Kelly serían:

- Una mezcla de bienes y servicios.

- Una mezcla de distribución.

- Una mezcla de comunicaciones.

\section{P.KOTLER: EL ORGANIZADOR DEL ESQUEMA DE MERCADEO DESDE LA ECONOMÍA COMO UNA “CIENCIA DE LA ESCASEZ".}

PRIMEROS 40AÑOS: 1962-2002.

Kotler y Zaltman involucraron un concepto económico-social en los temas de mercadeo, al definirlo como "el diseño, implementación y control de programas calculados para influir la aceptabilidad de ideas sociales, incluyendo consideraciones de planificación del producto, precio, comunicación y distribución”. Esto los llevaría a revisar la importancia de los elementos macroeconómicos, antes no contemplados en los esquemas de marketing, cuyo énfasis estaba dado sólo en aspectos micro-económicos. E igualmente, a plantear la necesidad de definir un marketing "social"; es decir, que por lo menos en teoría, colocara al consumidor como el eje central del problema bajo estudio y no se limitara a definir métodos y herramientas para apoyar los procesos de ventas.

Pero la particular concepción neoclásica de la economía como una "ciencia de la escasez", aceptada por Kotler ${ }^{10}$, lo llevará implícitamente a alejar esta ciencia aplicada del marketing -que él mismo define así-, de su real concepción como ciencia social.

Recordemos que para otras escuelas del pensamiento económico ${ }^{11}$, la economía no se centra únicamente en entender el problema de "la asignación de bienes escasos", regida por un supuesto principio de "neutralidad valorativa" (P. A. Samuelson); sino en esencia, es una ciencia social que

10. Ver el prefacio de su obra Mercadotecnia, Prentice-Hall Hispanoamericana, 1980, traducida de la primera edición en inglés "Principles of Marketing”, en la página. XXIII. donde al identificar el intento científico del nuevo paradigma, claramente muestra su concepción de que: "La ciencia económica nos recuerda que el mercadeo trata del uso de recursos escasos para satisfacer necesidades y por lo tanto, éstos deben asignarse cuidadosamente".

11. Desde los clásicos A. Smith y D. Ricardo, pasando por Marx, Keynes y las escuelas poskeynesiana y neoricardiana, todos comparten el acento social de esta ciencia y su método, a diferencia de los neoclásicos y sus congéneres más “modernos”: M. Friedman y P. A. Samuelson. Para mayor profundización ver Homero Cuevas T., Introducción a la Economía, Bogotá: Universidad Externado de Colombia. Guías de Clase, 1981, Capítulo 1: Objeto y Método de la Economía. 
se encarga del "estudio de las relaciones sociales de producción, distribución, acumulación y consumo del producto social", entre sus diferentes "actores" o mejor, fuerzas vivas de la sociedad que los neoclásicos las denominarían, "factores de la producción".

En esta línea, para Kotler "el marketing estudia específicamente cómo son creadas, estimuladas, facilitadas y valoradas las transacciones". Por ello, define el proceso de mercadeo en función de la manera como es posible atender los mercados o demanda, a partir de las decisiones fundamentales de la empresa: misión, objetivos y metas, estrategia de crecimiento y plan de negocios. Esto es lo que llamaríamos en un modelo, los parámetros. Algo que Kotler nunca plantea explícitamente, por lo cual sólo es posible hablar de su esquema de organización; no de un modelo como tal.

Tal vez surgen aquí los primeros interrogantes:

- Si se acepta que este sea el proceso de mercadeo, donde la misión parece ser un parámetro, ¿cómo garantizar que la misión de la organización esté realmente centrada filosóficamente en “atender y servir clientes”, como único mecanismo para garantizar rentabilidad, crecimiento y pervivencia de la organización a largo plazo?

- ¿Qué pasa con la visión? Una misión centrada en clientes asegura una "visión sana"; es decir, ¿sin ningún tipo de "enfermedades de visión"?12

- ¿Por qué muchos autores de mercadeo posteriores a Kotler y que utilizan y aceptan su esquema, plantean que la rentabilidad es un objetivo de mercadeo?, cuando en realidad ¿es claramente un parámetro o dato, que debe ser aceptado por el modelo y el Plan Estratégico de Mercadeo?

- ¿Por qué lo que Kotler llama "estrategia de crecimiento" está establecido dentro de los posibles parámetros de su esquema de mercadeo, cuando en esencia es la primera de las estrategias posibles de un modelo de mercadeo y así, se concreta como el primero -y algunas veces el más relevante, pero no el único- de los objetivos estratégicos de mercadeo?; es decir, una de las variables dependientes de un modelo de mercadeo, armado con los elementos de la ciencia.

Si se logran aclarar estos temas, lo siguiente sería revisar a fondo el llamado "proceso de mercadeo" planteado por Kotler. Allí, a los manejos de la mezcla de mercadeo, las cuatro pes, que denomina como el "desarrollo de una estrategia de mezcla de mercadeo competitiva" (paso 3 de su proceso de mercado), el autor antepone los siguientes elementos:

- La "identificación y análisis de las oportunidades de mercadeo" -debería ser, del mercado (paso 1 de su proceso de mercadeo).

12. Parafraseando el trabajo de Theodore Levitt, profesor de Harvard Business School, quien en un espectacular escrito publicado por primera vez en 1960, habló sobre la "miopía del mercadeo" (publicado en $L a$ esencia del Marketing, Vol. 1, Bogotá: Norma, 1996), pero dejó de lado otras posibles y aún más frecuentes enfermedades de la visión empresarial, que he detallado en un artículo reciente:"Marketing y enfermedades de la visión: una ampliación al planteamiento de Levitt”, artículo de trabajo sin publicar, preparado para el curso de Marketing Estratégico, de la especialización de Psicología del Consumidor de la Universidad Konrad Lorenz. 
- La "segmentación y selección de mercados objetivo" (paso 2 de su proceso de mercadeo).

Así, deja para el final, (como paso 4 de su proceso de mercadeo), el "diseño de los sistemas de gerencia de mercadeo que apoyen el planeamiento y control, información y personal de mercadeo".

Este proceso merece varios comentarios; pero el más relevante es de carácter más bien general: una vez que uno se deja centrar en los aspectos del Marketing Operativo, ya sea por que se crea que el corazón de "una estrategia competitiva y efectiva" está en las pes de Kotler, o porque simplemente éstas adquieren la relevancia que los autores, a partir de Kotler le han venido otorgando (algo que definitivamente no es responsabilidad de Kotler). Se entiende la idea de que, como "cada situación de mercadeo es única", según afirma Kotler, es imposible siquiera intentar identificar, modelar, construir y hacer seguimiento para controlar, aprender y mejorar, a un conjunto de relaciones estables o no en el tiempo; relaciones entre las llamadas variables de mercadeo, pes del mercadeo, mezcla, mix de mercadeo o marketing operativo y unas variables dependientes que hay que identificar y conceptuar claramente, antes de poder definir un modelo; en este caso, en el modelo de mercadeo, estaríamos hablando de los objetivos estratégicos .

Así, surgen otros cuestionamientos adicionales:

- ¿Será que los procesos de planeación de marketing pueden iniciarse únicamente a partir de la identificación de las llamadas "oportunidades del mercado"?
¿No faltará detenerse un poco más y desarrollar todo un diagnóstico estratégico? ¿No es así siempre en la metodología de trabajo de las ciencias, sean éstas básicas o aplicadas; pero mucho más necesario en las segundas?

- ¿Será que el diseño, desarrollo e implementación de sistemas de información del mercado (SIM) es una tarea que puede postergarse al último punto del proceso?; ¿no será que los proceso de investigación de mercados deberían estar incluidos allí, no como actos sueltos o esporádicos, sino precisamente, como parte de un sistema funcional? Qué debe incluir qué: el SIM a la investigación de mercados, o como plantea Kotler, la investigación de mercados al SIM?

- ¿No será que para poder definir y formular un modelo de la ciencia, entre la definición del mercado objetivo y las acciones (actions) o estrategias activas (active strategies) de mercadeo (o variables del mix de mercadeo), deben formularse unos objetivos estratégicos de mercadeo bien concretos que sirvan de conexión entre la verdadera estrategia y este conjunto de acciones que no son en esencia la estrategia, sino la táctica; es decir, el mercadeo operativo?

Pero cómo se concretan las llamadas "pes de Kotler":

- PRODUCTO: calidad, características, opciones, estilo, marca, empaque, tamaños, servicios, garantías, devoluciones.

- PRECIO: precio de lista, descuentos, 
deducciones, período de pago, términos de crédito.

- PROMOCIÓN: propaganda, venta personal, promoción de ventas, publicidad.

- PLAZA: canales, cobertura, localizaciones, inventario, transporte.

Tal vez a este respecto sólo caben tres observaciones más:

- ¿Cómo es posible armar un modelo de mezcla de mercadeo que no incluya las Actions o Active Strategies de Servicio al Cliente?; no me refiero a "los servicios" relacionados con el producto, máxime cuando estamos al frente de la producción y comercialización de intangibles.

- ¿Es realmente promoción, entendida como un incentivo adicional al producto, que se entrega por un período de tiempo corto, para impulsar el mercado, a lo que se refería Kotler? ¿No era más bien al conjunto de actividades que se utilizan para promocionar y promover un producto; es decir, a los aspectos de la comunicación comercial?; pero si así era, ¿por qué incluyó en la variable el tema de las fuerzas de ventas e igualmente, terminó hablando de promoción, allí sí, como incentivo, a los vendedores?; y si es así, ¿dónde quedó la promoción a los clientes; o esta sólo se realiza a costa de la variable precio?

- Teniendo claro que plaza significa distribución, ¿por qué de todas formas las variables allí identificadas terminaron dando explicación al problema de la ubicación, logística y localización geográfica de los puntos comerciales?; ¿y qué pasa cuando quien vende es el mismo que distribuye?

Nótese que a pesar del exceso de escritos de marketing sobre lo que supuestamente constituye el objeto de estudio de este paradigma naciente, las innumerables definiciones que aparecen en los textos de mercadeo sobre lo que constituye cada "variable" -en este caso variables independientes-, las otras -las dependientes- también están definidas en los libros, pero nunca aparecen identificadas como tal: crecimiento y participación de mercado; posicionamiento, y competitividad; ni se establecen ni definen sus relaciones, o se intenta construir un modelo de predicción para tratar el problema comercial: "es preferible adivinar que predecir".

Como si fuera poco, en la mayoría de los textos existen diferentes y en algunos casos, contradictorias definiciones, acerca del papel que cada variable debería desempeñar; así, el exceso de definición sólo conlleva a un bajo nivel de conceptuación, primer paso necesario en la construcción de modelos de la ciencia, y por ende, a una imposibilidad de formulación teórica y práctica del modelo de mercadeo.

Cuando alguno de estos aspectos que hemos identificado y cuestionado no funciona o no se amarra adecuadamente al modelo de mercadeo, ¿ya no sirve el modelo?; ¿necesitaríamos desarrollar otro modelo de marketing?; ¿se necesitan tantos modelos como empresas y situaciones mercado-producto existan?; ¡ es la casuística de cada negocio (léase, relación mercado-producto), un impedimento para poder conceptuar adecuadamente las partes de un modelo comercial o de marketing?; o más bien, ¿tendremos que estar permanentemente al garete de las 
coyunturas y las firmas de consultoría del momento, con su último best seller, y esperando el último grito de la moda en materia de mercadeo, para poder estabilizar este paradigma de la ciencia? Definitivamente, la respuesta es no. Hay que desarrollar un mercadeo amarrado a los principios de la ciencia; independientemente de que ésta, en la que estamos, sea una ciencia social y aplicada: una tecnología.

\section{STANTON, ETZEL Y WALTER: EL INICIO DE LA AGREGACIÓN DE MÚLTIPLES PES DEL MERCADEO, DESDELOS 70.}

El trabajo de William J. Stanton, Michael J. Etzel y Bruce J. Walker ${ }^{13}$ constituyó, a mi manera de ver, un avance interesante frente a los planteamientos anteriores, ya que logró ordenar algunos elementos de la mezcla de mercadeo, disminuyendo el exceso de "word game" centrado en supuestas pes, en el que se sumergió el tema desde los 60, y puso mayor atención en su razón central de ser. Así por ejemplo, definió bien el papel de la distribución, vinculando tanto el tema de canales de comercialización como de distribución; permitió establecer que el precio constituye la esencia misma del mercadeo financiero de una empresa, aunque persistió en separarlo del conjunto de variables del producto como tal; y finalmente, nos indicó que el papel primordial de la llamada "promoción" era de tipo informativo y persuasivo: dos papeles centrales de lo que es la comunicación comercial.

Igualmente, es mucho más clara la forma como se presenta la relación entre la investigación de mercados y el desarrollo y ubicación del sistema de información del mercado, dentro del esquema, lo cual adquiere además una relevancia y un giro significativo frente al planteamiento de Kotler. Adicionalmente, el papel que asigna a ciencias auxiliares del proceso como la psicología, la sociología y la antropología, así como a las herramientas brindadas por la estadística y la econometría, para apoyar el proceso estratégico de definición de mercados objetivos por la utilización de las herramientas de segmentación.

Sin embargo, este enfoque no impidió que se siguiera desarrollando una tendencia operacional y centrada en las llamadas "pes del mercadeo", en pleno proceso de crecimiento; y peor aún, una ya extendida metodología de enseñanza del marketing con ejemplos de empresas "supuestamente exitosos"; que en vez de permitir conceptuar y definir adecuadamente un modelo desde la ciencia, solo logró alejarnos cada vez más de esta meta. La desconexión entre la llamada mezcla de mercadeo y la forma como se deberían establecer las relaciones con el problema estratégico, con un modelo y con factores que relacionen tales variables, es evidente en el texto de Stanton. Las diferentes ediciones del libro (cada vez mayor en número de hojas y por supuesto, más costosas), son una oda a la casuística del marketing como modelo de aprendizaje.

No son los únicos; son parte del stablishman, de la pirámide, o cúpula de "sabios del marketing", que lógicamente tienen sus replicas criollas. Ni hablar del papel y de la relación entre este tema y el desarrollo de un millonario negocio de horas de consultoría internacional y local en mercadeo, ventas y servicio al cliente; así como en las

13. William J. Stanton, Michael J. Etzel y Bruce J. Walker, Fundamentos de Marketing, McGraw-Hill, 1992, novena edición. 
herramientas (software y hardware) que las empresas "deben adquirir", "so pena" de ser castigadas a largo plazo "por el mercado".

Pero, a pesar de tantos casos y ejemplos, horas hombre de consultoría y asesoría, programas y fierros, cursos y actividades académicas, libros publicados, etc., el marketing está lejos de constituir un cuerpo sólido de postulados de la ciencia, con un modelo claro de predicción completo, más no complejo, que permita orientar adecuadamente las decisiones comerciales.

Cada empresa debe aprender del modelo para manejar sus decisiones; pero no es que se requiera un modelo y un consultor para cada empresa.

Si fuera así, pensemos por ejemplo en un tema tan complejo como el cuerpo humano -y por qué no, como el cosmos-, que requiriera de la formación de expertos en medicina y en astronomía, cada uno de ellos con un "modelo a la medida" de cada caso bajo observación, análisis, estudio y "operación”; esto es, que la especialización en cada caso humano -o estrella-, requiriera de la intuición y la emoción individual, para poder atenderlo acertadamente. Y peor aún, que cada casuística invalidara los avances y el desarrollo de cada uno de sus modelos y métodos. Se esgrime la excusa de ser una ciencia social y aplicada, cuando es claro que las ciencias sociales y más las aplicadas no son exactas. Pero lamentablemente, en la mayoría de los casos, ni siquiera se acepta el tema como paradigma de la ciencia; es concebido como un arte, un oficio, una técnica bonita y sofisticada, pero al fin, una técnica; o simplemente, como una "acti- vidad humana" que no se puede medir, ni controlar. Mucho menos modelar para aprender del proceso.

\section{EL MERCADEO SEAFIANZA ENTRE LOS 80 Y 90 COMO MODASY ESTILOS GERENCIALES}

Las siete Ws del Mercadeo: un intento por hablar de estrategia:

- What (Qué)

- Who (Quién)

- Where (Dónde)

- When (Cuándo)

- Why (Por qué)

- Whence (De dónde)

- Wherefor (Para qué)

Las cuatro íes del servicio: aparece la variable pero no se involucra en los modelos.

- Intangibilidad

- Indivisibilidad

- Inconsistencia

- Inventario

Las cuatro ces del Mercadeo o de los clientes ${ }^{14}$ : la "revolución" de los 90 ante el desarrollo de las herramientas de CRM. Según sus pregoneros, "sustituya el mercadeo tradicional por el mercadeo del futuro. Sustituya por ello las tradicionales cuatro pes por cuatro ces":

- El producto se convierte en valor para el cliente.

- El precio se convierte en costo para el cliente, entendido aquel como la identificación de la relación costo beneficio.

- El lugar de venta ("plaza”) se convierte en comodidad y conveniencia.

14. Aunque se le atribuyen a Robert Lauterborn, en las primeras ediciones del libro "Dirección de Mercadotecnia" de Philip Kotler están igualmente identificados estos elementos como parte del andamiaje del problema por resolver en marketing.

El mercadeo está lejos de constituir un cuerpo sólido de postulados de la ciencia, con un modelo claro depredicción completo, más no complejo, que permita orientar adecuadamente las decisiones comerciales. 
- La promotión se convierte en comunicación al cliente, entendida como Comunicaciones Integrales y Creatividad al servicio de los clientes.

Este es uno más de esos recetarios, de los cientos que circulan semanalmente desde los EEUU y de los miles que se producen localmente en cuanto a Mercadeo. El planteamiento, que de por sí no es tan nuevo como algunos creen, refiere que en el contexto actual hay que abandonar las cuatro pes de Kotler (Product, Price, Promotion and Place) y sustituirlo por el de las cuatro ces del Mercadeo: cliente, costo, conveniencia y comunicación. Este tipo de mensajes resultan bastante jocosos, en dos sentidos:

1. Porque normalmente quienes los predican no tiene la más remota idea de lo que realmente es mercadeo, desde la perspectiva de la ciencia, y su importancia desde el punto de vista estratégico, para manejar una organización bajo una óptica comercial; casi siempre son "paquetes", supuestamente de conocimiento, adquiridos por personas expertas en ventas o en publicidad, pero con un manejo conceptual bastante bajo. Eso sí, de gran renombre, poder, o lo que es peor, al frente del departamento comercial de alguna importante empresa, atendida por una firma de consultoría y asesoría en "temas de mercadeo”. Simultáneamente, son asumidos de manera casi inmediata y sin mayor discusión o revisión teórica, por sendos grupos de académicos, profesores y/o asesores, en temas comerciales, que los trasmiten de manera automática e irresponsable a sus estudiantes, so pre- texto de la necesaria "actualización" que exige el mundo empresarial, comercial y el mismo mercadeo.

2. Porque no sólo hay que abandonar las mal llamadas cuatro pes de Kotler, que como ya sabemos no son de Kotler; y promotion ya no puede ser entendida como si promotion a clientes y "Promotion" de ventas fueran lo mismo y adicionalmente, como si ellas incluyeran los actos de la comunicación comercial; y place nunca puede ser pobremente traducido como plaza o sitio de distribución. Sino en general, es necesario rechazar cualquier otro tipo de receta operativa, medio esotérica; incluyendo estas supuestas cuatro pes del mercadeo. Ésta, al igual que muchas otras modas, no constituye sino una versión de novela, ridícula y poco profunda, de lo que puede constituir realmente el marketing como ciencia.

En esta misma línea se encuentran los denominados "nueve puntos Kotler" de una compañía exitosa:

1. La compañía selecciona mercados y nichos donde disfruta de ventajas frente a sus competidores. Abandona o evita aquellos donde se encuentre en una situación de debilidad.

2. Todos los empleados y departamentos deberán estar orientados al cliente y al mercado.

3. Debe de haber una buena relación de trabajo entre marketing, ventas, investigación y desarrollo, y producción.

4. Debe existir una buena relación de trabajo entre marketing, ventas y servicio al cliente. 
5. La compañía debe tener una política de "incentivos" para fomentar un adecuado comportamiento del consumidor.

6. La compañía debe construir y guiar continuamente la satisfacción y la lealtad del cliente.

7. La compañía debe desarrollar un sistema de distribución en colaboración con sus proveedores y distribuidores.

8. La compañía debe estar calificada para construir una fuerte imagen de marca.

9. La compañía debe ser flexible a la hora de afrontar los requerimientos de sus clientes.

No terminaríamos si incluyéramos todas las modas empresariales, gerenciales y de marketing; sin embargo, vale la pena mencionar las siguientes; algunas con referencia clara de autores y años; otras, fundamento de cursos, programas, asesorías, "cambios de rumbo" y un inimaginable número de participantes y actores usufructuando en la cadena:

- La teoría X de la empresa. McGregor. 1960.

- La teoría Z de la administración. Ouchi W. G. 1982.

- Las diez reglas de la calidad en el servicio. Jan Carlson. 1985.

- Marketing de guerra. Al Ries y Jack Trout. 1986.

- Marketing de abajo hacia arriba. Al Ries y Jack Trout. 1988.

- Marketing total. N. P. Braidot. 1990.

- Marketing global. P. Drucker, 1991.

- Las diez reglas de la investigación eficaz. P. Drucker, 1992.

- Las 22 leyes inmutables del marketing. Al Ries y Jack Trout, 1993.
- Marketing relacional: lealtad y rentabilidad. Joseph Alet. 1994.

- Las siete claves del éxito de los campeones del marketing o maximarketing. Stann Rapp y Thomas L. Collins. 1994.

- Marketing "one to one". Don Peppers, Martha Rogers y Bob Dorf. 1995.

- Marketing de redes neuronales, Network Marketing. Amway, 1995.

- "Benchmarking": lo último en estrategia competitiva. Jerome P. Finnigan. 1996.

- Las cuatro caras de la individualización masiva. James H. Gilmore y B. Joseph Pine II. 1997.

- El nuevo posicionamiento de marketing. Al Ries y Jack Trout, 2000.

- Marketing radical. Sam Hill y Glenn Rifkin. 2000.

- La calidad total.

- Los círculos de participación.

- El enfoque "cero errores".

- La reingeniería de procesos.

- La administración por objetivos.

- La planeación estratégica por escenarios.

- Empoderamiento y facultamiento.

- El poder total al cliente.

- La organización horizontal con pirámide invertida.

- Administración por liderazgo centrado en couching.

- Gerencia centrada en cuadro de mandos y balanced scorecard, de Kaplan y Norton.

- Mega marketing.

- Hiper marketing.

- Marketing holístico

Tal vez sólo se salvaría de este cuadro la teoría L -Manual de Antigerencia- de Jean- 
Paul Sallenave (1995), que corresponde a una crítica bastante interesante de las tendencias en el mundo de la administración y el mercadeo.

\section{ILDEFONSO GRANDE (ESPAÑA) Y JEAN-JACQUES LAMBIN (FRANCIA): EL REENFOQUE EN MARKETING ESTRATÉGICO Y ECONOMÍA}

El marketing no es un conjunto de técnicas que se aplican para facilitar las ventas. Por el contrario, es una filosofía de la actividad de la empresa que debe impregnar a los gestores y a sus actividades.

Con los trabajos de Ildefonso Grande (1992) ${ }^{15}$, profesor titular de la facultad de Ciencias Económicas y Empresariales de Bilbao, en la Universidad del País Vasco; y Jean-Jacques Lambin (1995) ${ }^{16}$, profesor de la Universidad Católica de Lovaina, podemos afirmar que se abre una nueva fase para el desarrollo del marketing como ciencia aplicada.

En su introducción, Grande afirma categóricamente y en contra de las formas tradicionales de enseñanza y ejecución del mercadeo, lo siguiente: "El marketing no es un conjunto de técnicas que se aplican para facilitar las ventas. Por el contrario, es una filosofía de la actividad de la empresa que debe impregnar a los gestores y a sus actividades"17. Más adelante indica que ante el enfoque y metodologías predominantes, se hace necesario replantear el tema: "Los responsables de la gestión del marketing deben conocer instrumentos de análisis económico. Quizá pocas veces los apliquen, pero sin duda habrán adquirido la capacidad de análisis y de deducción, que les ayudarán en la gestión de su actividad". ${ }^{18}$

Sin embargo, tal vez uno de los aportes más relevantes del trabajo de Grande esté en su observación de la necesidad de lograr definir modelos con capacidad de predicción, una vez que estén claros los conceptos que enmarcan la actividad del mercadeo. Lograr aterrizar cuantitativamente la "toma de decisiones", midiendo y aprendiendo de la experiencia y redefiniendo la estrategia a la luz de los resultados tácticos, es sin lugar a dudas uno de los pilares fundamentales del desarrollo del paradigma.

De esta manera Grande concluye que:

El marketing es una ciencia del comportamiento -que ha tomado conceptos de otras ciencias- que intenta explicar las relaciones de intercambio. Es también una ciencia joven, como la Economía, de la que se deriva. Su contenido, relativo al intercambio, se rodea del estudio del comportamiento de los consumidores, vendedores, competidores, instituciones y del entorno. Todavía no ha alcanzado su madurez, por que una ciencia madura tiene la capacidad de anticipar, no como el mercadeo que avanza con base en prueba y error. ${ }^{19}$

Por su parte, Lambin hace énfasis en la necesidad de desarrollar y definir de manera mucho más clara "los fundamentos ideológicos de la gestión del marketing”. Así, aunque todos los autores hablan de estrategias de marketing, Lambin exige definir y separar claramente los elementos que constituyen el marketing Estratégico, de aquellos que tradicionalmente se han enseñado y ejecutado en las empresas, que corresponden al llamado "Marketing Operativo".

15. Ildefonso Grande, Dirección de marketing: fundamentos y software de aplicaciones, Madrid: McGraw-Hill, 1992.

16. Jean-Jacques Lambin, Marketing Estratégico, París : McGraw-Hill, 1995.

17. I. Grande, Op.Cit., p. XXIII.

18. Ibíd., p. XXIV

19. Ibíd., p. 20. 
En la primera parte agrupa todos aquellos elementos que permiten realizar la "gestión de análisis sistemático y permanente de las necesidades del mercado"; en tanto que en la segunda ve claramente las tácticas o "programas de distribución, de precio, de venta y de comunicación.” 20

Así, Lambin propone, por primera vez en marketing, que se separen y entiendan los elementos de acción, (cómo conquistar los mercados) análisis (cómo comprender los mercados); e ideología (cómo entender y atender, filosóficamente, el mundo de los negocios), para poder construir un modelo del proceso de mercadeo.

Para este autor, esta será la única manera de acabar con las concepciones centradas en los mecanismos de publicidad y ventas; o aquellas que hacen énfasis únicamente en el papel de los métodos de investigación, reservadas para grandes empresas con capacidad logística y recursos suficientes; o peor aun, la visión que desde afuera plantean sus detractores, de un marketing como arquitecto de una sociedad de consumo, corruptora de las necesidades reales de la gente; es decir, una ciencia que se entienda de la siguiente forma: "El marketing es el proceso social, orientado hacia la satisfacción de las necesidades y deseos de individuos y organizaciones, por la creación y el intercambio voluntario y competitivo de productos y servicios generadores de utilidades." 21

La división planteada por Lambin, en lo que considero es el primer intento de definir un modelo de marketing como tal (ver gráfico 1), es la siguiente:

- Marketing estratégico ("gestión de análisis")

- Análisis de las necesidades: definición del mercado de referencia.

- Segmentación del mercado: macro y microsegmentación.

- Análisis del atractivo: mercado potencial -ciclo de vida.

- Análisis de competitividad: ventaja competitiva defendible.

- Elección de una estrategia de desarrollo.

- Marketing operativo ("gestión voluntarista”).

- Elección del(los) segmento(s) objetivo.

- Plan de mercadeo (objetivos, posicionamiento, táctica).

- Presión mercadeo integrado (cuatro pes): producto, puntos de venta, precio, promoción.

- Presupuesto de marketing.

- Puesta en marcha de un plan y control. 


\section{Gráfico 1. El proceso de mercadeo según J.-J. Lambin}

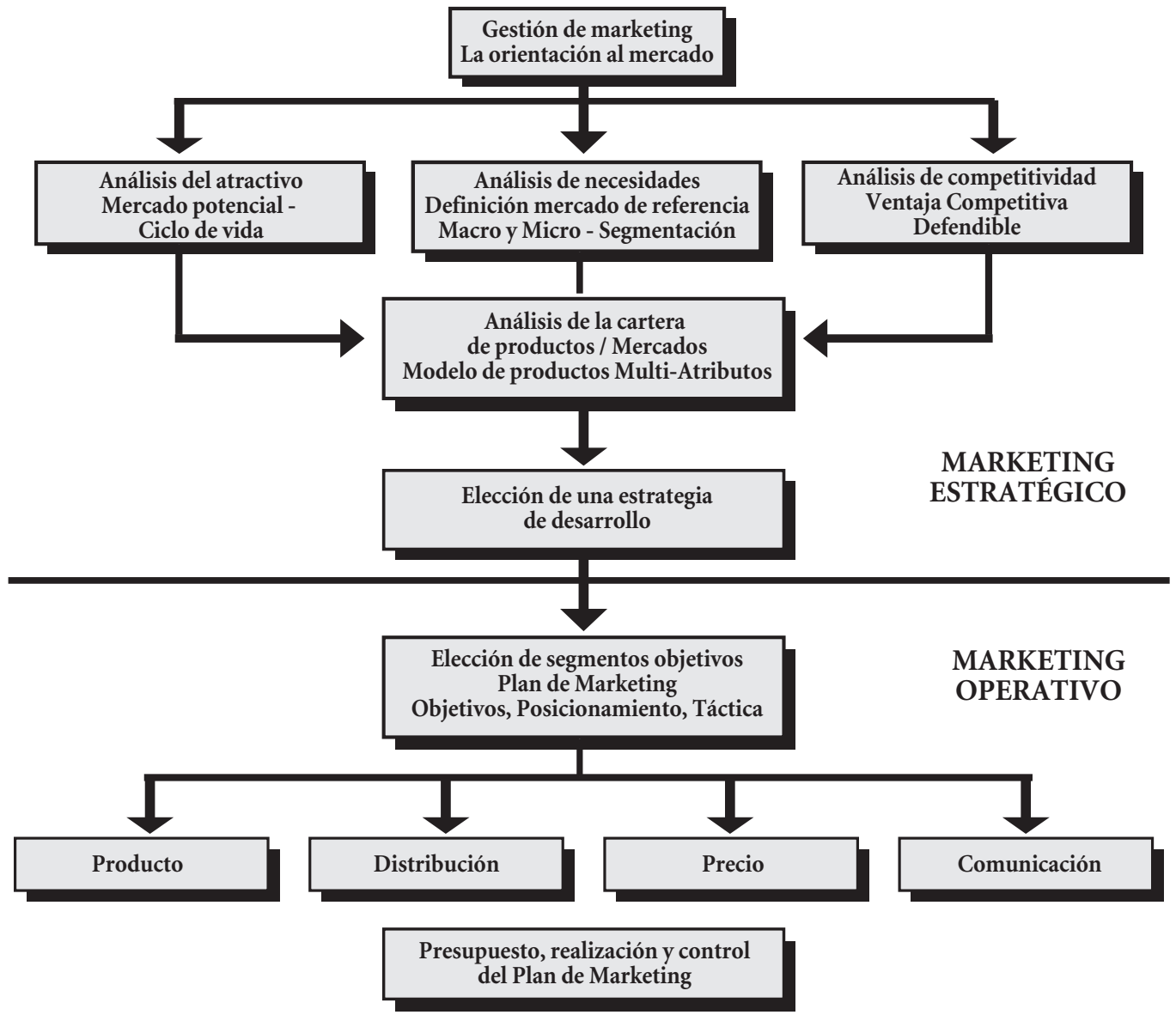

Sobre este modelo vale la pena hacer las siguientes reflexiones:

- La competitividad y el desarrollo o crecimiento, son dos de los tres elementos estratégicos básicos; faltaría adicionar el tema del posicionamiento, que en el modelo de Lambin aparece como parte de un tema operativo del plan de marketing.

- La segmentación del mercado no es una estrategia; es una herramienta de las ciencias económico-administrativas, que permite definir una estrategia de enfoque; es decir, lograr establecer los mercados potencial, objetivo y meta, a largo, mediano y corto plazo respectivamente. Igualmente, la elección de los segmentos objetivo no es un planteamiento táctico o del mercadeo operativo. Es definitivamente la primera de las decisiones de la estrategia de marketing.

- Definir una "cartera de productos" (relaciones producto-mercado), no es algo previo al problema estratégico del desarrollo (o crecimiento); es algo que está inmerso en este objetivo estratégico y suele adelantarse mediante 
herramientas que esta ciencia aplicada puede definir claramente.

- No existe explícitamente dentro del modelo un concepto de sistema de información del mercado, como parte del problema estratégico, sino una serie de labores sueltas en cada una de las fases del proceso de mercadeo; así, en la misma línea de P. Kotler, el control al plan de marketing no aparece como una tarea central del SIM, sino como un tema del mercadeo operativo, al final del proceso.

- Finalmente, su variable comunicación es mucho más clara y mejor conceptuada que en la mayoría de los textos de mercadeo, desde P. Kotler, en los cuales la "promoción" es la actividad de promocionar o promover a través de mensajes de comunicación y no actos de incentivos a corto plazo; sin embargo, al igual que en los demás planteamientos de marketing, el tema del servicio al cliente no está incluido en el modelo de mercadeo como variable del "mix", independientemente de que lo toque tangencialmente; e incluso, en su última edición, incluye "nuevos métodos para medir la satisfacción-insatisfacción del cliente", como parte del arsenal para medir los comportamientos de respuesta de los compradores. Es decir, a nuestra manera de ver esta ciencia aplicada, como parte de la Investigación de Mercados debe cobijar el Sistema de Información del Mercado.

Podemos concluir aquí que Grande y Lambin comparten una visión del marketing como ciencia social aplicada, cuyo punto de partida es la teoría económica; pero cuestionan seriamente aquellas hipótesis de la Teoría Neoclásica, que ha llevado necesariamente a prestar atención a los factores de oferta y que implícitamente ha mantenido centrado el marketing en los temas operativos; aún en medio de amplias afirmaciones sobre el papel de las "necesidades de los consumidores" en la toma de decisiones empresariales. O peor, donde todos los aspectos del proceso de mercadeo terminan convirtiéndose en "estrategia", incluso una herramienta o instrumento, como la segmentación del mercado. Este elemento, más la necesidad de construir y trabajar con modelos de predicción y la separación de lo estratégico frente a lo operativo constituyeron sin lugar a dudas, un avance significativo en el desarrollo de este joven paradigma.

\section{EL MARKETING CONTRA-INTUITIVO COMO UNA CIENCIA APLICADA, PERO IGUALMENTE SOCIAL (COMO SU CIENCIA BASE: LA ECONOMÍA) \\ 1. PORTER, BIESYtrout Y LAS RECIENTES IDEAS DE KEVIN J. CLANCYY PETER METER C. KRIIEG (2000).}

Frente a la visión clásica de centrar el objetivo de marketing estratégico -la estrategiade manera casi unívoca en el problema del crecimiento, desde 1980 Michael Porter había planteado la relevancia de la variable objetivo competitividad, como eje central de la estrategia de mercadeo ${ }^{22}$. De la misma manera, para el mismo año Al Ries y Jack Trout habían insistido sobre la importancia de la variable objetivo posicionamiento, igualmente para ellos (y de manera radical, "la única realmente válida y relevante

22. Véanse los tres trabajos de Porter, durante casi 15 de años de investigación, sobre el particular: M. Porter, Estrategia competitiva. CECSA, 1985; M. Porter, Ventaja competitiva. CECSA, 1990; y M. Porter, La ventaja competitiva de las naciones. Madrid: Plaza y Janés, 1991. 
Elelemento central de la acciónque hallevado al desastre empresarial con el que correlacionan el bajo nivel de desempeño de la economía norteamericana en la última década, es el uso permanente del "programa de decisiones IT"; es decir, "intuicióny testosterona”. a largo plazo"), como el eje central de la estrategia de marketing. ${ }^{23}$

Para el año 2000 los señores Clancy y Krieg $^{24}$ llaman la atención sobre la importancia de los dos temas, desde la perspectiva estratégica, y muestran que las empresas deberían centrar sus objetivos de marketing en:

1. Construir marcas fuertes: posicionarse de manera clara, sucinta y con marcas de gran poder.

2. Competir haciendo las escogencias apropiadas: construir una ventaja competitiva con estrategias que tengan como punto de partida la información científica. No la intuición de los administradores.

Tal vez uno de los elementos más revolucionarios del trabajo de Clancy y Krieg está en la manera como soportan estadísticamente sus planteamientos, y demuestran que en los EEUU, pese a todos los postulados, escuelas, consultorías, programas de formación y exigencias laborales en la contratación del personal de marketing, y contra todo pronóstico, visto desde lo que se les vende y ofrece a los países del tercer mundo, "la gente de marketing no está haciendo su trabajo”. De manera jocosa afirman que el problema está en la "teoría de los $M B A$ ”; es decir, en lo que ellos denominan, los "Murders Brands Assestments".

Según sus estudios, en EEUU, para el año 2000, de 48 categorías relevantes de productos tangibles e intangibles, 39 de ellas -el 75\%-, muestran una tenden- cia clara de decline del "Brand Equity" a mediano plazo.

Consecuente con su agradable explicación, el elemento central de la acción que ha llevado al desastre empresarial con el que correlacionan el bajo nivel de desempeño de la economía norteamericana en la última década, es el uso permanente del "programa de decisiones IT"; es decir, “intuición y testosterona”.

Algunos de los elementos que se asocian a dicho programa son:

- Poco tiempo para entender y conocer las verdaderas necesidades de los consumidores.

- Exigencia centrada en los resultados a corto plazo.

- Énfasis en los juicios de marca (identidad visual) y no en los "Brand Equity" (estrategia y sustancia del posicionamiento de marca).

- Falta de claridad en el llamado "targeting” para definir la estrategia de posicionamiento.

- Un proceso de mercadeo (y especialmente de la comunicación comercial) más basado en el entretenimiento, que en la información científica.

Así, según los autores, los "gerentes de mercadeo" y sus jefes no conocen, ni tienen clara la conexión entre sus posibles “inputs”, operación de las llamadas variables de la mezcla de mercadeo, con sus "outputs" o resultados del proceso

23. Véase el trabajo inicial de Ries y Trout sobre este tema, al cual se irían añadiendo algunas dosis muy particulares de "modas" y "píldoras varias" que pienso que no aportaron nada al ya completo y serio planteamiento inicial. Incluyendo su trabajo más reciente, sobre un supuesto "nuevo posicionamiento": Al Ries y Jack Trout, Posicionamiento: El concepto que ha revolucionado la comunicación publicitaria y la mercadotecnia, McGraw-Hill, 1990. (primera versión en inglés publicada en 1980).

24. Kevin J. Clancy y Peter C. Krieg, "Counter-Intuitive Marketing: Achive Great Results using Uncommon Sense”, The Free Press, New York, 2000. 
comercial; y ello les lleva permanentemente a operar con:

- Defensas empíricas.

- Supuestos sobre la realidad, sin modelos basados en información real de los mercados y mediciones probabilísticas.

- Imposibilidad de cuantificar, medir, controlar y poder aprender del proceso de mercadeo.

Su conclusión es contundente: se necesita afinar el proceso de mercadeo desde la ciencia, con "un modelo matemático que establezca tales relaciones y permita acabar con las prácticas intuitivas". Esto es lo que definen como un "mercadeo contra-intuitivo", en su forma de ver, es una sumatoria de ciencia y arte:

- Ciencia: modelo, análisis rigurosos, errores y medidas probabilísticas asociadas, y bases de datos impecables.

- Arte: creatividad y sueños centrados en la realidad de los mercados; no en las emociones de sus administradores.

Como corolario de lo anterior, plantean la necesidad de:

1. Volver al consumidor; si es que alguna vez hemos estado allí.

2. Establecer un modelo matemático que relacione el mayor número de variables posibles y no atienda solamente a las operativas.

3. Definir el plan de marketing, con una clara conceptuación de cada uno de sus elementos.
4. Implementar (llevar a cabo), sin permitir que la subjetividad esté por encima de la información científica.

5. Hacer seguimiento: medir, controlar, aprender y redefinir la estrategia a partir del manejo táctico.

Esto significa que por primera vez, en la corta historia del marketing, alguien desde la academia y la consultoría se ha atrevido a poner en tela de juicio los planteamientos definidos desde el "stablishman" de la "pirámide del conocimiento" y supuestamente universalmente aceptados por grupos de seguidores y consultores en todo el mundo. E incluso, cuestionando con información relevante, el buen funcionamiento del mercadeo en los países desarrollados y especialmente, en los EEUU. No sobra recordar, como ya dijimos, que este último hecho ya había sido cuestionado por Jean Paul Sallenave, en su Manual de Antigestión $n^{25}$, al cual ya he hecho referencia.

\section{EL MODELO DE JORGE GARCÉS(1995-2004) 26}

Desde 1995 he venido enseñando, difundiendo en el contexto laboral, trabajando y desarrollando simultáneamente, un modelo de marketing, como ciencia aplicada, que tenga su punto de partida en la ciencia básica origen de los temas que se abordan en mercadeo; es decir, la teoría económica. Pero no una versión parcial y amañada de la economía; es decir, aquella que sólo acepta y utiliza las formulaciones teóricas de los paradigmas clásico y neoclásico; sino una mucho más

25. J. P. Sallenave, La teoría “l” de la administración. La antigestión, Bogotá: Norma, 1995.

26. Los puntos de vista que aquí se muestran han sido parte vital del material de trabajo de los cursos de Marketing Estratégico y Marketing Operativo que propuse, diseñé y comencé a enseñar, para los estudiantes del postgrado de Psicología del Consumidor, de la Universidad Konrad Lorenz, desde 1995. Igualmente, han sido totalmente documentados en los diferentes lugares de trabajo, cursos, seminarios, capacitaciones, asesorías y consultorías, que he realizado para varias empresas, entidades, instituciones y universidades, desde hace varios años: Jorge Enrique Garcés Cano, Visiones dinámica, sistémica y funcional de la Planeación Estratégica de Mercadeo (PEM), 1995-2004, D. R. A. (sin publicar). 
completa, que incluya las aproximaciones y desarrollos desde otras esquinas de esta maravillosa ciencia social, a saber:

\section{- Los cuestionamientos de Carl Marx}

a clásicos y neoclásicos, que permitieron entender los aspectos de la producción capitalista y sus ciclos expansivos y recesivos, mucho antes de que se diera la primera gran crisis depresiva, en los años 30 del pasado siglo; e igualmente, su teoría del valor trabajo, que desnudaría la visión tradicional sobre la formación de precios y así, permitiría integrar y entender mejor los aspectos de la distribución y el consumo. Igualmente, que desde la perspectiva sociológica y antropológica, nos permita ver y entender el mundo, y concebir al ser humano inmerso en él, no simplemente como una "maquina hedonista de placer", cuyo único fin social sea la "maximización de sus satisfacciones individuales" (o sea, ganancias, salarios, rentas, etc.); donde los actos individuales per sé se aseguren que siempre estarán premiados socialmente, sobre los actos conjuntos o colectivos. Esa forma particular de concebir al ser humano corresponde a una etapa específica del desarrollo social; pero jamás podrá ser aceptada como un fin en sí mismo, de la evolución del hombre. Y aunque aparezca como un tema irrelevante a la problemática del mercadeo, este es el verdadero sustento teórico para un marketing en el presente siglo. ${ }^{27}$

- La revolución keynesiana a los planteamientos de su maestro Alfred Marshall, que permitirían entender mucho mejor los aspectos macroeconómicos del proceso; así como asegurar una mayor comprensión de dos de los aspectos psicológicos más relevantes del proceso de acumulación de capital: "la propensión marginal a consumir"(por el lado de la demanda); y "la aversión al riesgo", como un elemento fundamental para determinar la eficacia marginal del capital (por el lado de la oferta).

- Los avances teóricos y empíricos de las teorías poskeynesianas de Joan Robinson a Alfred Eichner, que permitieron entender mejor muchos de los fenómenos macroeconómicos a partir de la explicación e integración de algunos aspectos microeconómicos, especialmente, por el comportamiento y las decisiones de algunos de los llamados "agentes económicos" en el proceso de producción. Más específicamente, de empresas agrupadas en sectores industriales con estruc-

27. Es paradójico que aunque el tema ya es claro en las llamadas ciencias naturales (por ejemplo, en neurología y astronomía), los investigadores sociales (cada vez más escasos) pretenden mantener identificada como "una ley de la evolución" el fenómeno de los actos sociales individuales, como maximizadores y eficientes per sé. Para más detalles es necesario remitirse a los trabajos de Rodolfo Llinás, El Cerebro y el Mito del Yo: el papel de las neuronas en el pensamiento y el comportamiento humanos, Bogotá: Norma, 2002; y Carl Sagan, El mundo y sus demonios: la ciencia como una luz en la oscuridad, Barcelona:. Planeta, 1995. En ambos casos hay una descripción amplia y poderosa de cómo neuronal o estelar (según cada caso), y como las organizaciones tienden a premiar (evolutivamente hablando), los procesos de desarrollo colectivo, frente a las manifestaciones e intenciones individuales. No sólo por una posible eficacia de "masas críticas", sino porque los grupos de trabajo sinérgico son definitivamente mucho más eficientes. 
turas sectoriales mayoritariamente oligopólicas y sus conductas empresariales. Por ejemplo, la relación entre inflación y decisiones de precios en empresas con elevados poderes de oligopolio y sobre todo, con grandes poderes económicos y elevados grados de monopolio.

- Finalmente, la necesidad de utilizar algunas de las más modernas herramientas de la econometría, en particular, y la de estadística en general, para poder construir modelos que posibiliten una estabilización y aplicación del marketing, como ciencia social aplicada.

El resultado de este ejercicio profesional es lo que he venido transmitiendo y aportando en el mundo laboral y acadé- mico; razón por la cual, desde la óptica de la ciencia, deben necesariamente definirse claramente y conceptuarse los elementos que constituyen el todo y las partes de ese proceso que describo en el cuadro guía que he denominado Visión Dinámica del Mercadeo. (Ver Gráfico 2).

Sin embargo ella, aunque engloba a las demás, por sí sola no permitiría una completa definición de lo que este proceso constituye, ni mucho menos del objeto y marco de estudio del marketing como ciencia social aplicada. Se requiere adicionalmente una visión sistémica así como su visión funcional. Solo a la luz del establecimiento de estas tres esquinas del proceso de mercadeo, es posible amarrar el paradigma al único norte posible y sostenible a largo plazo: la ciencia.

\section{Gráfico 2}

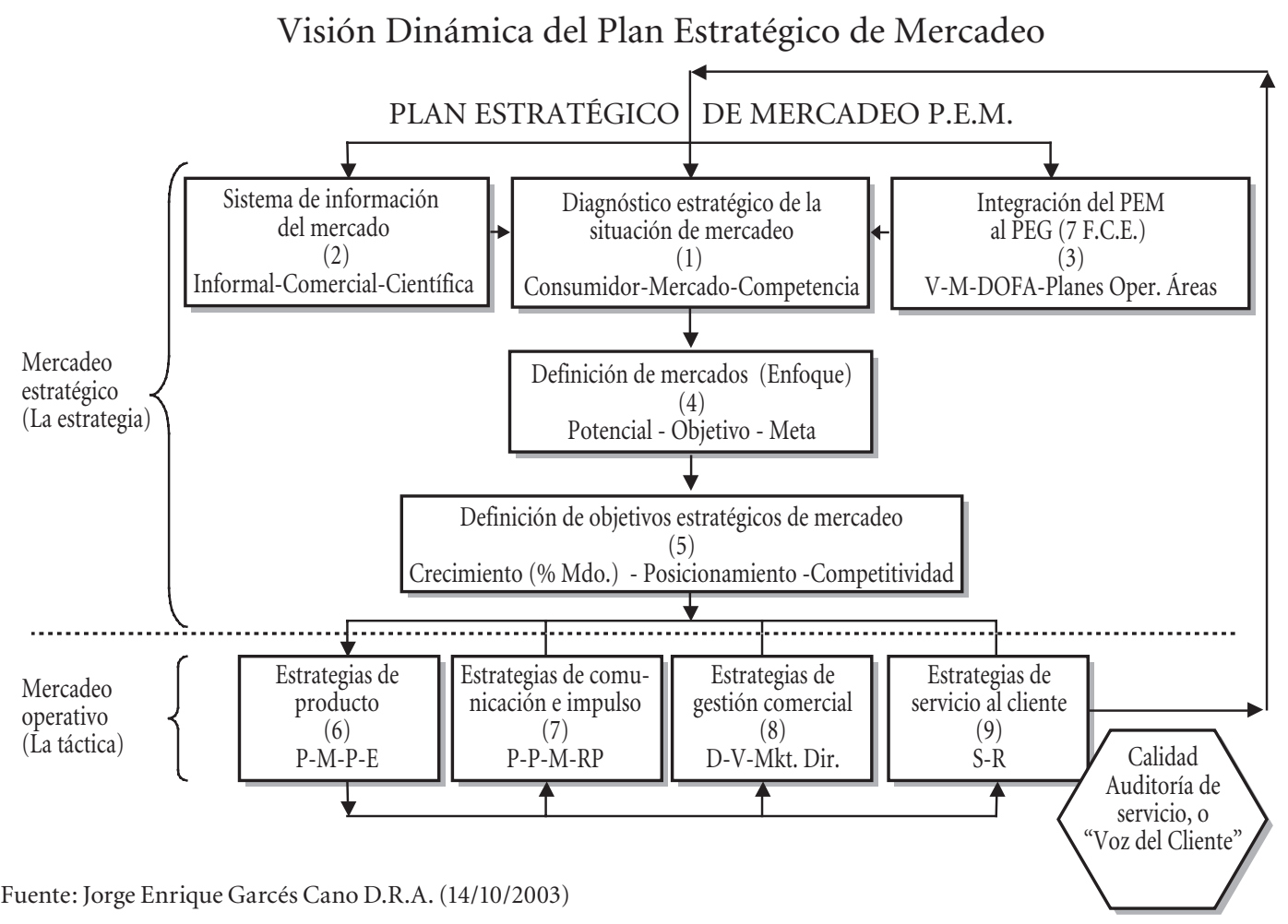


Las tres esquinas del modelo de marketing:

- Sistémica: de la coordinación de sistemas; esto es, un conjunto ordenado de principios, con coherencia y un método, que permitan relacionar de manera ordenada las estructuras de un cuerpo del conocimiento, en este caso el Marketing, de tal forma que se puedan establecer las interrelaciones existentes entre todos y cada uno de sus componentes (partes de un sistema).

- Dinámica: fuerza que produce movimiento y en su acción, se convierte en el movimiento mismo. En éste caso, de dónde y hacia dónde se dirigen las fuerzas que imprimen el movimiento de los mercados para poder establecer las direcciones del movimiento del Plan Estratégico de Mercadeo (de ahora en adelante, PEM). ¿Por qué lado del proceso del mercado vienen determinadas estas fuerzas? Por el lado de la oferta (teorías clásica y neoclásica); o por el lado de la demanda (Marx, Keynes y poskeynesianos, entre otros).

- Funcional: Relativo a las funciones que deben realizar cada uno de los componentes o módulos de un sistema; en este caso, los módulos del PEM. Pero en términos más estrictos, la necesidad de definir claramente las variables dependientes (Objetivos Estratégicos de Mercadeo) e independientes (mezcla de mercados) del modelo de mercadeo; sus rutas de interacción y la forma como se pueden entender y medir sus correlaciones. Esto es, la definición de un modelo matemático para entender su funcionamiento, medirle, controlarle, aprender de la experiencia, corregir y desarrollar alguna capacidad predictiva.

Entendido así, el marketing debe ser definido como una ciencia aplicada con origen en la ciencia económica; pero más específicamente, en aquélla parte de la teoría económica que se encarga de estudiar los aspectos relacionados con las decisiones y acciones de los llamados "agentes económicos": empresas y consumidores; esto es, la microeconomía.

¿Cómo definir entonces el objeto y cuerpo de estudio de este joven paradigma? ¿Qué clase de ciencia es ésta? ¿Cuál es su método central? ¿Cuáles son sus alcances y sus límites? ¿Hasta dónde llega y dónde comienza a tomar elementos de su ciencia básica y punto de origen -la economía- o de otras ciencias paralelas como la psicología y la Administración de Empresas, que desde su perspectiva podrían ser simplemente ciencias auxiliares? ¿Cómo armar y construir un modelo que permita estabilizar y entender el funcionamiento de sus partes?

Lo primero en establecer es que el marketing, al igual que la economía, la administración y la psicología, es una ciencia social; es decir, no es ni una técnica empresarial ni una herramienta de la administración; ni mucho menos, un cúmulo inconexo y desordenado de recetas y fórmulas gerenciales al arbitrio del autor, el libro o la tesis de moda que alguna importante firma de consultoría internacional esté difundiendo en el mundo académico y empresarial.

Podríamos establecer que así como la economía es una ciencia social "que se encarga del estudio de las relaciones sociales de producción, distribución, acumulación y consumo, entre los diferen- 
tes agentes económicos", el mercadeo se concreta entonces, como ciencia aplicada, pero igualmente social, al estudio de aquellos aspectos que determinan las relaciones entre oferentes y demandantes, para garantizar los procesos de intercambio que se generan en los mercados; es decir, se circunscribe a la identificación de algunos de los aspectos económicos que determinan la producción y el consumo, para asegurar el intercambio de valor, (no necesariamente de equivalentes, tal como lo afirma la teoría neoclásica, entre la oferta y la demanda).

Así, esta ciencia social aplicada utiliza igualmente la historia, es decir, la información de la relación de intercambio como su método central de análisis, con el fin de construir modelos de comportamiento del consumidor- que le permitan ir aprendiendo permanentemente de esa relación que se ha establecido en los mercados, entre productores y consumidores; $y$ al entender cómo se comportan en el tiempo estos factores determinantes de oferta y demanda de productos tangibles e intangibles, puede, a partir de tal información, desarrollar estrategias y tácticas, cuya relación debe necesariamente buscar una orientación hacia la predicción, bajo el principio central de "incertidumbre en los mercados" y no garantía automática de supuestos "equilibrios entre ofertas y demandas”. Con márgenes de error calculados, niveles razonables de riesgo y probabilidades asociadas de éxito mayores a las que brinda el azar puro (50-50); es decir, la intuición.

Esto nos permite concluir, que siendo una ciencia social y comportándose como tal, no puede ni debe salirse de aquellas reglas del juego definidas para la ciencia en general y que permiten diferenciarla de la no ciencia o anticiencia; por no utilizar el nombre que más fácilmente definiría el fenómeno: el esoterismo ${ }^{28}$. Y así mismo, siendo una ciencia aplicada, no puede permitirse ni académica, ni empresarialmente, que cada quien conceptúe y defina a su acomodo las relaciones existentes entre las diferentes partes que constituyen su modelo de aplicación, cuando formulan un modelo, que las modas terminen definiendo su norte y orientación académica y empresarial; o peor aún, que se termine aceptando la idea esotérica de que su aplicación práctica está regida por un supuesto principio de relatividad vulgarmente entendido, como afirman algunos: "en mercadeo todo depende de todo", y que por ello, su ejercicio dependa mucho más de un supuesto sentido común que de otra cosa.

Es decir, que puede más la intuición que la información validada; que cualquier estrategia sirve, siempre y cuando esté bien sustentada; que cualquier acción, constituye una estrategia; que no hay diferencia entre estrategia y táctica, porque "una táctica es simplemente una estrategia más micro"; por lo tanto, que no hay diferencia entre los elementos que constituyen lo uno y lo otro, o que establecerla es de irrelevante en el mundo laboral; que hacer mercadeo es poner a operar y mezclar un cúmulo de acciones del mercadeo mezcla: de producto, de precio, de promotion (que no es lo mismo que promoción como incentivo) o de "place" (que no es lo mismo que plaza), etc.

En suma: no podemos seguir permitiendo que el bajo nivel conceptual y la

28. Para apoyar la reflexión ver la diferenciación que a este respecto establece Carl Sagan, en su monumental trabajo Op. Cit. 
incapacidad de definir y construir modelos con intenciones predictivas, desde la perspectiva de la ciencia y con algunas de sus relaciones matemáticas establecidas para cada relación mercado-producto, dentro de una empresa, la casuística, siga atentando contra las posibilidades de desarrollo del marketing y difundiendo una visión que
Elplan estratégico de mercadeo (PEM) debe entenderse como pensamiento yplaneación secuencial de estrategias, tácticas y actividades, conquistar: acercar, seducir mercado". necesarias para y retener "el fácilmente podemos ahora sí rotular de anticientífica y en la mayoría de los casos lamentablemente, de esotérica.

De esta manera, el plan estratégico de mercadeo (PEM) debe entenderse como pensamiento y planeación secuencial de estrategias, tácticas y actividades, necesarias para conquistar: acercar, seducir y retener "el mercado" -entendido como-, la demanda, con "productos" que satisfagan las necesidades de los consumidores (léase, la oferta), consolidando la permanencia y el crecimiento rentable de una organización a largo plazo, en dicho mercado. Algo que sólo será posible si logramos establecer a largo plazo relaciones sostenibles con algunos grupos de consumidores, en cuyo proceso estos son el punto de partida y así mismo, el de llegada.

Estamos entonces hablando de aquellos procesos que nos permiten identificar, crear, comunicar y entregar -o sea, distribuir- valor: valor de uso (subjetivo), por el lado de la demanda; y valor de cambio (objetivo), como sustento material de la capacidad de crear valor para el productor o accionista, por el lado de la oferta.

Así las cosas, sólo es posible definir las tácticas y actividades en función de la estrategia; y ésta, debe concretarse para garantizar su identificación, viabilidad, consisten- cia y coherencia consigo misma y con las demás estrategias, cuantificación y medición (mensurabilidad), en los denominados objetivos estratégicos de mercadeo; éstos, por ahora, se definirán y agruparán en tres grandes bloques:

- Crecimiento y participación de mercado, a corto plazo.

- Posicionamiento, a mediano plazo.

- Competitividad (constitución de ventaja competitiva), a largo plazo.

Por su parte, la segmentación no es una estrategia; es una técnica o herramienta de las ciencias económico-administrativas, que permite ir subdividiendo el mercado, de lo más general (macro-segmentos o segmentos naturales) a lo más particular (micro-segmentos), con el objetivo de identificar los "mejores" 29 para ser atendidos en el tiempo, frente a los ofrecidos actualmente (mercado actual), del mercado total:

Corto plazo (un año) $=$ Mercado meta Mediano plazo (dos a tres años) $=$ Mercado objetivo

Largo plazo (máximo cinco años) = Mercado potencial

¿Qué lentes o filtros utiliza la técnica? : geográficos, demográficos, sicográficos y /o comportamentales.

- Criterios geográficos: regiones, zona urbana o rural, tamaño de la población, clima y relieve, etc.

- Criterios demográficos: edad, sexo, tamaño y ciclo de la familia, distribución del ingreso, profesión-ocupa-

29. Los criterios para determinar qué segmentos son o no "mejores" para aprovisionar en el tiempo son múltiples; entre ellos estarían: su tamaño, sus niveles de concentración y homogeneidad, la facilidad o el grado de dificultad para su acceso, la cercanía o lejanía (física o virtual), sus posibilidades de generación de ingresos, etc. 
ción, educación, religión, raza, origen exterior-nacional, etc.

- Criterios sicográficos: clases sociales, estilo de vida, personalidad, etc.

- Criterios comportamentales del consumidor: ocasión de compra, beneficios que busca, lealtad a las marcas-empresas, frecuencias de uso, sensibilidad a la "seducción" comercial (al vendedor, a los canales alternativos, a ofertas y promociones, etc.), entre otros.

Hay que recordar que un "mercado", visto desde el punto de vista de quien está pensando en hacer la oferta, es un grupo de personas naturales o jurídicas con necesidades o deseos que estén soportados por una capacidad real de compra; o sea, que se identifica con el concepto económico de demanda. Pero visto desde su contraparte empresarial, además de la intención de satisfacer las necesidades de los consumidores, diferenciarse y ser competitivos, las empresas para acercarse a estos mercados persiguen un objetivo específico de obtener beneficios económicos y para lograrlo, deben poseer capacidad de producción y aprovisionamiento; es decir, el concepto económico de oferta.

Un mercado entonces puede ser definido en función de varios conceptos:

\section{Tamaño:}

a. Valorado en unidades monetarias (1.000 MM de pesos colombianos).

b. Medido en unidades de volumen (30.000 gaseosas, 10.000 CDT, etc.). c. Según el número de clientes (100.000 consumidores del producto por un período específico de tiempo, como por ejemplo un año).
2. Tiempo: definido según la naturaleza de cada negocio /empresa (relación mercado / producto).

a. Corto plazo (un año).

b. Mediano plazo (dos años).

c. Largo plazo (tres a cinco años).

3. Segmento: una parte significativa del mercado, agrupada según criterios preestablecidos, con el fin de conformar grupos homogéneos que faciliten el desarrollo de una estrategia de mercadeo y mejoren los niveles de respuesta e impacto.

a. Total: $100 \%$ o total de personas $\mathrm{y} / \mathrm{o}$ entidades que tienen una necesidad latente para ser satisfecha con un producto tangible o intangible, independientemente de que tal deseo se haya o no hecho explícito.

b. Actual: total de ventas-consumo de un sector, o de una empresa según sea el caso, en un momento específico.

c. Potencial: de interés para la empresa a largo plazo (tres a cinco años).

d. Objetivo: de interés para la empresa a mediano plazo (dos años).

e. Meta: de interés para la empresa a corto plazo (un año).

\section{VARIABLES DEPENDIENTES DEL MODELO DE MARKETING:}

\section{LOS OBJJTIVOS ESTRATÉGICOS DE MERCADEO.}

Podemos ahora sí plantear como hipótesis central, que en el modelo de marketing las variables dependientes son los objetivos estratégicos de mercadeo (OEM); es decir, la manera como ha sido concretada la estrategia, para posibilitar su seguimiento y medición: 
1. Crecimiento: a corto plazo, es necesario establecer cómo permanecer en el mercado y crecer; es decir, ganar una participación real de mercado. El indicador de crecimiento económico y participación de mercado que defina la empresa, dependerá de la visión de sus accionistas y su enfoque de negocios. Sin embargo, como hemos estado hablando del proceso histórico de construcción de una relación de consumo a largo plazo, entre oferentes (empresa) y demandantes (clientes), lo lógico es centrar el indicador en un portafolio de clientes rentables, capaces de generar el valor esperado por los accionistas, si y sólo si, hemos sido capaces, a través de la relación, de generarle valor a los clientes. Hay que recordar que es en esencia un proceso de intercambio de valor.

2. Posicionamiento: a mediano plazo, se requiere definir cómo ubicar la empresa y/o sus productos en la mente de los consumidores, y lograr marcas de valor creciente para la organización. No se trata simplemente de ubicarse en una buena posición cuantitativa en las mentes de los mercados potenciales, cuya medida estadística puede ser el máximo indicador (top of mind). Sino de lograr una adecuada posición, cerrando las brechas entre el posicionamiento cualitativo logrado y el esperado; e igualmente, la brecha entre su indicador numérico y el de compra, recompra y/o referencia positiva.

3. Competitividad: a largo plazo, es necesario definir el camino de cómo se logrará la tan anhelada ventaja competitiva ${ }^{30}$. No una lista de posibles ventajas comparativas; sino aquella razón por la cual el consumidor se ha decidido en nuestro favor y estaría dispuesto a seguirlo haciendo, dado que califica mejor nuestra propuesta de valor, a largo plazo.

Se tendría entonces que validar si la construcción y el desarrollo de esa relación con clientes a largo plazo, mediada por los procesos de intercambio de valor con fuerzas diferentes a cada lado de la ecuación, en la demanda como en la oferta, depende o no del mayor nivel de logro de los tres OEM definidos en el modelo; esto es, si son o no estas las variables dependientes de un modelo de mercadeo. Y con ello claro, ahí sí, definir, conceptuar y vincular las variables independientes de dicho modelo, y la manera como pueden ser manejadas.

\section{VARIABLES INDEPENDIENTES DEL MODELO DE MARKETING: LA MEZCLA DE MERCADEO.}

Como factores estadísticos, o grupos de variables estabilizadas, cuya naturaleza y comportamiento permite agruparles para entender mejor su funcionamiento, su sinergia y las relaciones que establecen entre ellas mismas, con los demás factores estadísticos, o conglomerados de variables y lógicamente, con las variables dependientes del modelo de mercadeo, de las cuales dan explicación:

- El producto global: características técnicas del producto, marca, empaque y precio.

- La comunicación comercial: publicidad, promoción, merchandising y relaciones públicas con enfoque comercial. moda más e incluso, es una simple redundancia; si es competitiva, es sostenible. 
- La gestión comercial: canales físicos de comercialización o ventas, canales de distribución física, campañas de marketing directo y canales virtuales (alternativos y/o complementarios) de ventas y/o distribución, si se requieren.

- El servicio al cliente: programas de retención, recuperación, mantenimiento, satisfacción y fidelidad de clientes.

Para tratar de interpretar sus relaciones, es necesario remitirse al gráfico de interacción de variables, definido para el modelo de marketing PEM-JEGC (1995-2004), D. R. A. (Ver Gráfico 3).
Allí se establece cómo el proceso de mercadeo debe comprenderse como un completo (no complejo) modelo de relaciones entre variables, con mayor o menor nivel de intensidad de relación entre cada grupo, dependiendo del tipo de mercado-producto al que nos estemos enfrentando.

De la capacidad de los analistas de mercadeo para estudiar, modelar y entender tales relaciones, dependerán sus posibilidades de éxito en la implementación de los planes estratégicos de mercadeo. Es la única forma seria de combatir y acabar con la práctica generalizada del "marketing Intuitivo", las modas y cualquier otro planteamiento esotérico.

\section{Gráfico 3}

\section{Relación OEM - Mezcla}

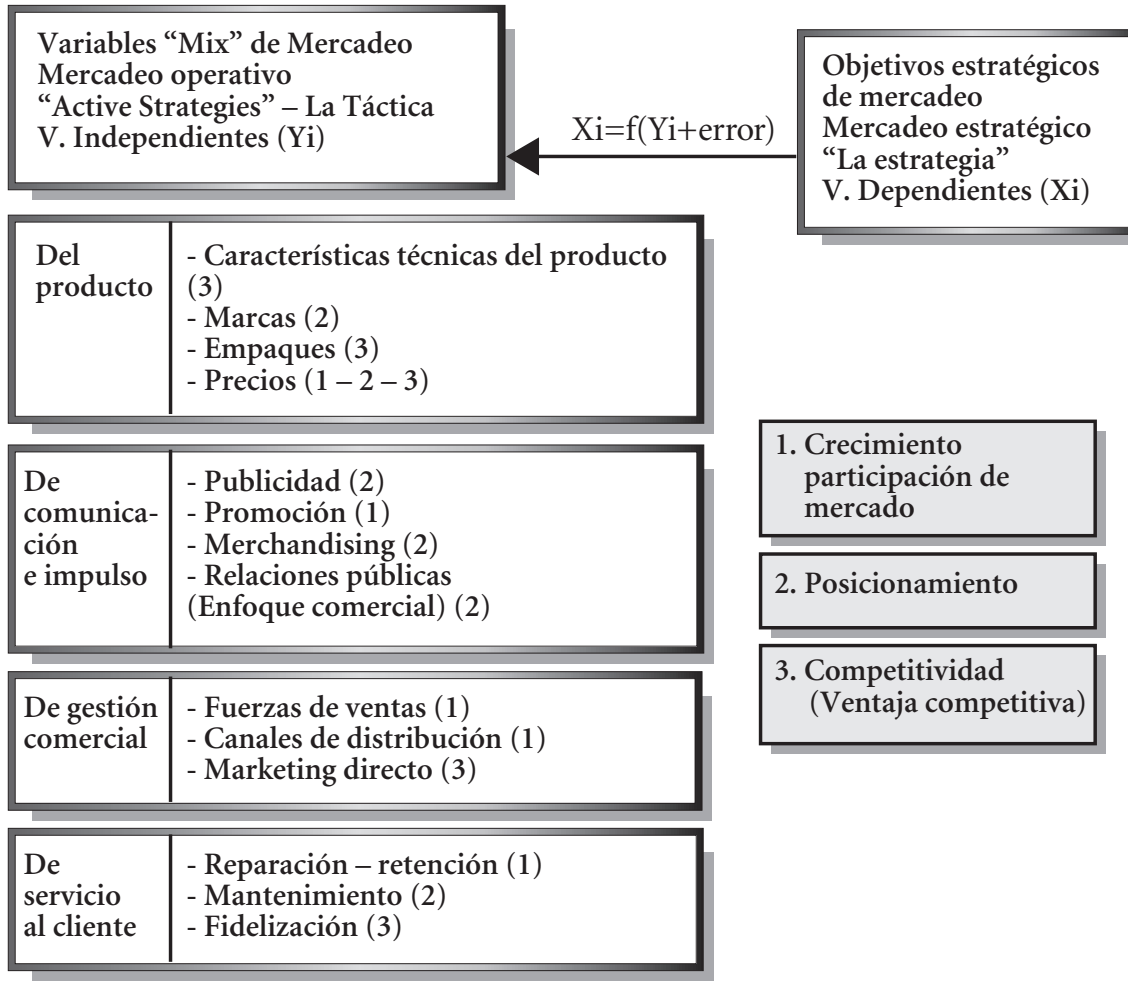

Fuente: Jorge Enrique Garcés Cano D.R.A. (14/10/2003) 
La estructuray funcionalidad de un equipo de marketing es algo que sigue a la estrategia. Sin ella, nunca será posible entendero conformar la estructura apropiada.
Es fundamental entender que cada empresa, negocio, relación mercado -producto, presenta condiciones específicas que deben ser seguidas y cuantificadas por el analista de mercadeo; sin embargo, podríamos establecer entre las variables dependientes del modelo de mercadeo (los OEM) y las independientes (la mezcla de mercadeo), algunas relaciones generales evidentes en los resultados y la historia de los últimos 50 años de experiencia comercial, en este modo de producción capitalista.

Cada relación indica una mayor correlación entre las variables, con las cuales se pueden anticipar algunas conclusiones generales, aún antes de iniciar seguimientos estrictos a los resultados comerciales, contra las inversiones realizadas en la mezcla de mercadeo, que podrían ser de gran utilidad en las decisiones del analista.

No deben olvidarse otros efectos, so pena de incurrir en prácticas economicistas y enfoques reduccionistas:

- Las variables independientes también poseen correlaciones entre ellas mismas (por ejemplo, precio contra promoción).

- También generan efectos de autocorrelación con fenómenos de rezago en el tiempo; de esta forma, una campaña con énfasis de inversión en las variables. La publicidad, podría generar impactos en los OEM, que no necesariamente se verificarían totalmente en el PEM a corto plazo.

- Los modelos requieren ser alimentados con información relevante y oportuna; aun en las mejores condiciones de mercadeo, trabajan bajo márgenes razonables de error controlado.

- Por lo tanto, no son mecanismos de predicción infalibles y su único fin es apoyar la toma de decisiones comerciales con herramientas que vayan más allá del ya ganado 50-50 que garantizan las leyes del azar. Sin embargo, hay que recordar que existe una gran diferencia entre predecir y adivinar. Lo primero, un acto de la ciencia, lo segundo, un campo claro del esoterismo.

En la misma línea, para su aplicación práctica, el cierre del proceso tiene que ver con algo que permanentemente olvidan los administradores de empresas y los hombres de mercadeo: la relación existente entre estrategia y estructura; ¿qué debe anteceder a qué?:

1. La esencia es enfocar las organizaciones hacia el mercado (léase, la demanda; es decir, los clientes o consumidores). No hacia los productos u oferta.

2. La única forma de lograrlo es a través del trabajo en equipo; esto es, una interacción coordinada de los diferentes grupos de segmento-portafolio óptimo de productos.

3. La clave es la proyección hacia el mercado por segmentos, concebida desde el origen de los productos, hasta las labores de post venta y servicio al cliente.

4. La estructura y funcionalidad de un equipo de marketing es algo que sigue a la estrategia. Sin ella, nunca será posible entender o conformar la estructura apropiada.

5. En el tiempo (ver Gráfico 4), la estructura de mercadeo, con una interacción 
matricial de liderazgo por grupos de trabajo segmento-productos, tiene responsables de temas a corto plazo (en el Gráfico C.P.): cómo crecer rápidamente y ganar participación de mercado; responsables de temas a mediano plazo (en el Gráfico M.P.): cómo posicionar las diferentes marcas institucionales y del portafolio (de productos, servicios y valores agregados), en la mente de los consumidores sean o no clientes actuales; y, responsables de temas a largo plazo (en el Gráfico L.P.) cómo construir y consolidar la ventaja competitiva.

6. Finalmente, el tema de enfocar el mercado (utilizando las herramientas de segmentación adecuadas); así como, construir el sistema de información del mercado, negociar con los aprovisionadores internos los factores claves de éxito que se requieran para maximizar el cumplimiento de los OEM y minimizar el riesgo; y generar un mecanismo permanente de diagnóstico de los mercados, que posibilite, premie y afiance el pensamiento estratégico (claro, colectivo) del equipo comercial y de toda la organización, siempre corresponderá al máximo nivel no necesariamente jerárquico, de un área de mercadeo. Lamentablemente la práctica empresarial suele ser totalmente inversa. En nuestro grafico corresponde a una ruta que llamaremos dinámica (D).

\section{Gráfico 4}

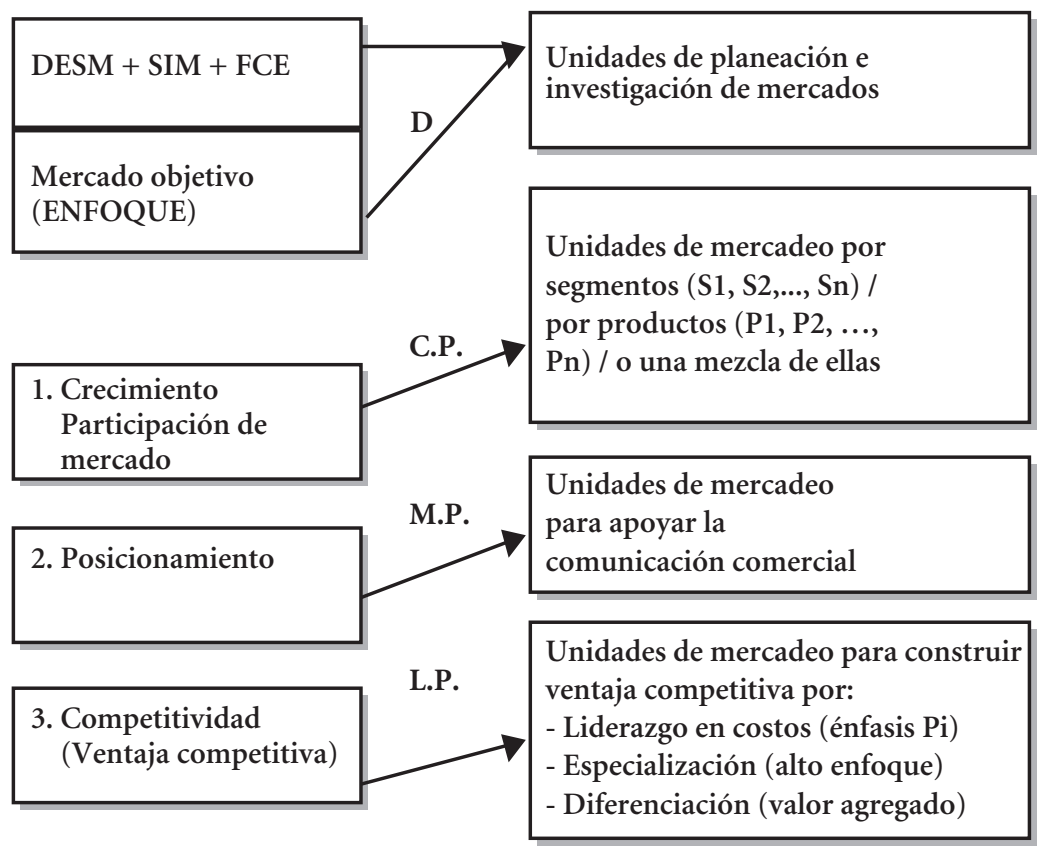

Fuente: Jorge Enrique Garcés Cano D.R.A. (14/10/2003) 
Finalmente, no importa que esta sea una ciencia social y aplicada; requiere de:

- Conceptualización.

- Definición de la teoría o cuerpos teóricos guía.

- Identificación del modelo.

- Variables dependientes e independientes en el modelo.

- Definición clara de roles para las variables.

- Identificación del todo y las partes.

- Interacciones.

- Coherencia y consistencia interna.

- Necesidad y suficiencia explicativa.

- El fin como ciencia: capacidad predictiva.

- Aplicación práctica (lo funcional): Un modelo para medir, controlar y aprender de la experiencia.

Parafraseando al profesor Homero Cuevas, quien afirma que: "Los economistas disponen del instrumental adecuado para eliminar la inflación, así como los militares disponen del instrumental adecuado para iniciar una guerra mundial; pero el permiso para usar tales instrumentos depende finalmente del poder político y de una decisión de carácter político"31, es evidente que igualmente hoy en día la mercadotecnia tiene sentadas las bases para construirse como un paradigma de la ciencia. Sin embargo, la mayoría de las decisiones académicas y empresariales siguen en manos de un puñado de tecnócratas, que lejos están de sentirse seducidos e interesados por permitir que sea el poder centrado en el conocimiento lo que las determine; para ellos es mucho mejor perpetuar un statu quo, donde es el poder centrado en la fuerza -emoción e intuición-, lo que aún se impone, alimentado permanentemente por las dosis y recetas administrativas y de mercadeo, del gurú de moda, sin ninguna rigurosidad o discusión científica y abierta sobre los contenidos y sustentos de cada nueva "fórmula" salvadora.

\section{NOTAS FINALES: EL “NUEVO” KOTLER Y SU“MODELO DE MARKETING HOLISTIICO"}

Esta revisión quedaría incompleta si no mencionara el hecho de que desde finales de la década pasada se ha generado una especie de contracorriente a los planteamientos que ya podemos denominar tradicionales, sobre estos temas del mercadeo.

Desde los trabajos de Stephen C. Buernett (1994) y Bobby J. Calder (1995), de la Universidad de Northwestern ${ }^{32}$; pasando por George S. Day (1996), de la Universidad de Pennsylvania ${ }^{33}$; hasta los más recientes planteamientos de Frederick Webster $(2003)^{34}$, sin mencionar otros autores (Doyle, Gummensson y el mismo Kotler, entre otros), el giro de los planteamientos ha sido casi unívoco:

1) La necesidad de reenfocar los temas del mercadeo al estudio de las relaciones de intercambio de valor, a largo plazo, y sus procesos de "exploración, creación y entrega de valor".

2) La necesidad de aclarar el papel de lo realmente estratégico, frente a los temas

31. Homero Cuevas T., Op. Cit., cap. viii, p. 353.

32. Stephen C. Burnett, Strategic Marketing J. L., Kellogg Graduate School of Management, Nortwestern University, 1994; y Bobby J. Calder, Strategic Consumer Marketing J. L., Kellogg

33. George S. Day, Market Driven Organizations: Building Marketing Capabilities, The Warton School, University of Pennsylvania, 1996.

34. Frederick Webster, Market-Driven Management, American Marketing Association, 2003. 
operativos (tácticas) que fueron premiados durante más de cuatro décadas.

3) La necesidad de prestar atención a los temas de la demanda; es decir, del consumidor, frente a una tradición que pese a esfuerzos teóricos aislados, ha sido claramente proclive (y económicamente neoclásica) a concentrarse en temas de producción y oferta (el producto, la publicidad y /o las ventas).

4) La necesidad de definir de manera explícita (no tácita) un modelo de mercadeo, que sea capaz de organizar la conceptuación de esta joven ciencia.

P. Kotler no podía quedarse al margen de esta arrolladora tendencia, y en sus dos más recientes trabajos ${ }^{35}$, el padre de la mercadotecnia, replantea muchos de sus focos originales, y se decide, por fin, a plantear explícitamente un modelo de marketing, que además, se centre en los temas estratégicos del proceso que llama: "esquema de marketing holístico".

Allí, a las que él denomina como tres actividades de exploración, creación y entrega de valor, le atraviesa los procesos, que también llama "funciones" relevantes: gestión de la demanda (concentración en el cliente), administración de los recursos (identificación de las competencias esenciales de la compañía) y gerencia de la red (desarrollo de la red de colaboradores). A estos, clientes, compañía y colaboradores, los denominará "los tres actores del proceso".

En sus cruces $\left(3^{\star} 3\right)$ se establecen los nueve componentes básicos del modelo y en su interior, quedarán definidas las que el llama "plataformas competitivas".

\section{COMPONENTE BÁSICOS:}

1. Espacio cognitivo

2. Espacio de competencia

3. Espacio de los recursos

4. Beneficios del cliente

5. Dominio empresarial

6. Socios empresariales

7. Gestión de la relación con el cliente

8. Administración de los recursos internos

9. Gestión de la asociación empresarial

\section{PLATAFORMAS COMPETITIVAS:}

1. Ofertas de mercado

2. Arquitectura empresarial

3. Actividades de mercadeo

4. Sistema operacional

No es el interés de este escrito hacer una evaluación de éste, calificado por el mismo Kotler, como un "novedoso" planteamiento; sin embargo, vale la pena reflexionar en algunas de las afirmaciones con que lo sustenta:

- Según el mismo Kotler, su modelo tiene como origen o punto de partida tratar de explicar cómo la economía, los mercados y así las relaciones en su interior, han sido seriamente transformadas por la internet, el mundo de los espacios y mercados virtuales y su máximo grado de "concreción": la actual "economía digital". Se le olvida a Kotler que desde hace ya bastante tiempo los mercados y la economía en general, no son ni se comportan como las viejas teorías económicas clásica y neoclásica nos habían descrito; no es

35. Philip Kotler, El Marketing según Kotler,. Madrid: Paidos, 2001; y Philip Kotler, Dipak C. Jain y Suvit Maesincee, El Marketing se mueve: una nueva aproximación a los beneficios, el crecimiento y la renovación. Madrid: Paidós, 2002. 
la Internet la que ha invalidado los viejos supuestos neoclásicos de equilibrio en los mercados, rendimientos decrecientes (costos crecientes), competencia perfecta (con el cúmulo de supuestos adicionales que ella encierra), etc., sino la realidad misma del funcionamiento del los aparatos productivos y las relaciones sociales de producción, en la economía capitalista.

- De la misma manera, no es Internet la que ha hecho o dejado obsoleto el planteamiento operativo y de baja capacidad explicativa para el desarrollo del mercadeo, centrado en las pes; ellas, en su esencia, nunca estuvieron cerca siquiera de ayudarnos en el proceso científico de interpretar las relaciones en los mercados, entre consumidores y productores; sólo reforzaron la visón produccionista y ofertista esgrimida desde el viejo paradigma neoclásico.

- Asimismo, tampoco será la Internet a quien le corresponda el papel y la relevancia que le está adjudicando Kotler: venir a ocupar el sitio de la vieja "mano invisible" de Adam Smith, como el nuevo mecanismo garante de un capitalismo donde por fin la información volverá a circular de manera ubicua (no asimétrica) y perfecta; esto es, que siente nuevamente las bases de la competencia "perfecta" y ¿por qué no?, que se convierta en la respuesta "salvadora" y perpetua de un modo de producción que desde hace ya bastantes años ha dado claros síntomas de enfermedad, cuando se deja y sigue suponiendo que "las libres fuerzas del mercado", guiadas por el interés individual, conllevan automáticamente a la eficiencia; o peor aún, al bienestar colectivo ${ }^{36}$.

Podríamos cerrar diciendo, que desde una perspectiva científica social, es imposible hablar de "el fin de la historia"; y el modelo de marketing requerido para interpretar las relaciones en los mercados al futuro. En este o en cualquier nueva forma o mutación del actual modo de producción, sólo será aquel que sea identificado y construido con elementos y planteamientos de la ciencia; ese es su único norte posible, so pena de morir condenado al olvido por haberse maquillado de "moda y casuística".

\section{BIBLIOGRAFÍA}

- AAKER, D. A. y Day, G. S. (1988). Investigación de Mercados. México: McGraw-Hill.

-ANSOFF, I. (1968). Estrategia Corporativa. McGraw- Hill: New York.

-ALDERSON, W. y Cox, R. (1948): “Toward a theory of marketing". En: Journal of Marketing, Vol. 13, pp. 137-152.

- AlderSON, W. (1965). Dynamic Marketing Behaviour: a functionalist theory of marketing. Illinois: Homewood, Richard D. Irwin, Inc.

- BAGOZZI, Richard P. (1975). "Marketing as Exchange”. En: Journal of Marketing, Vol. 39, No. 4, pp. 32-39.

•BARTELS, R. (1968). “The General Theory of Marketing”. En: Journal of Marketing, Vol. 32, pp. 29-33.

36. Para este tema en particular, ver las críticas demoledoras a tales planteamientos de J. Stiglitz, Premio Nobel de Economía 2001: Joseph E. Stiglitz,. Los felices 90: la semilla de la destrucción. Madrid: Taurus, 2003. 
- BURNETT, Stephen C. (1994). Strategic Marketing. J. L., Kellogg Graduate School of Management, Nortwestern University.

- BUTLER, R.; DEBOWER, H. y JONES, J. (1914). Marketing Methods and Salesmanship. New York: Alexander Hamilton Institute.

- CALDER, Bobby J. (1995). Strategic Consumer Marketing. J. L., Kellogg Graduate School of Management, Nortwestern University.

- CAVES, R., y PORTER, M. (1977). "From entry barriers to mobility barriers: Conjectural decisions and contrived deterrence to new competition". En: Quarterly Journal of Economics, Vol. 91, pp. 241-262.

- CHAMBERLIN, E. (1933). The Theory of monopolistic competition. Cambridge: Harvard University Press.

- CLANCY, Kevin J. y KRIEG, Peter C. (2000). Counter-Intuitive Marketing: Achive Great Results using Uncommon Sense. New York: The Free Press.

- CUEVAS T., Homero (1981). Introducción a la Economía, Guías de Clase. Bogotá D.C.: Universidad Externado de Colombia.

- DAY, George S. (1990). Market Driven Strategy: Processes for Creating Value. New York: The Free Press.

- DAY, George S. (1996). Market Driven Organizations: Building Marketing Capabilities. Pennsylvania: The Warton School, University of Pennsylvania.

- DAY, George S. (2000). "Capabilities for Forging Customer Relationships". En: Marketing Science Institute, Report Summary\# 00-118, pp. 1-33.

- DAY, George S. y VAN DEN BULTE, Christophe (2002). "Superiority in Customer Relationship Management: Consequences for Competitive Advantage and Performance". En: Marketing Science Institute, Report Summary \# 02-123, pp. 141.

- EL-ANSARY, A. (1979). "The General Theory of Marketing: revised". En: Conceptual and Theoretical Developments in Marketing. Ferrells, Brown y Lamb eds. Chicago: American Marketing Association, pp. 399-407.

- FREY, Albert W. (1961). Advertising. Nueva York: Ronald Press, (3a . Ed.).

- GRANDE, Ildefonso (1992). Dirección de Marketing: fundamentos y software de aplicaciones. Madrid: McGraw-Hill.

- GRÖNROOS, Ch. (1989). "Defining Marketing: A Market-Oriented Approach". En: European Journal of Marketing, Vol. 23, No. 1, pp. 52-60.

- GUMMESSON, E, (1987). "MarketingLong Term Interactive Relationship", Research report. En: Grönroos, Ch., Defining Marketing: A Market-Oriented Approach, op. cit. Stockholm: Stockholm University.

- GUMMESSON, E. (1991). "Marketing Orientation Revisited: The Crucial Role of the Part-Time Marketer". En: European Journal of Marketing, Vol. 25 No. 2, pp. 6075

- HUNT, S., MUNCY, J., RAY, N. (1981). "Alderson's general theory of marketing: a formalization.” En: Review of Marketing, Ben M. Enis y Kenneth J. Roerings, eds., Chicago: American Marketing Association, pp. 267-272.

- KOTLER, Philip (1962). Mercadotecnia. México: Prentice-Hall Hispanoamericana, (traducida de la primera edición en ingles "Principles of Marketing", 1962).

- KOTLER, Philip. y LEVY, Sidney (1969). "Broadening the Concept of Marketing". 
En: Journal of Marketing, Vol. 33 pp. 1015.

- KOTLER, P. y ZALTMAN, G. (1971). "Social Marketing: An Approach to Planned Social Change". En: Journal of Marketing, Vol. 35 pp. 3-12.

- KOTLER, Philip (1972). Marketing Management. New Jersey: Prentice Hall, 1972.

- KOTLER, Philip (1972). "A Generic Concept of Marketing”. En: Journal of Marketing, Vol. 36, pp. 46-54.

- KOTLER, Philip (1984). "Rethink the Marketing Concep”. En: American Marketing Association News, $\mathrm{N}^{\circ} 18$.

- K O T L E R, Philip ( 1986 ). "Megamarketing". En: Harvard Business Review, N64, pp. 117-124.

- KOTLER, Philip (2001). El Marketing según Kotler. Barcelona: Paidós.

- KOTLER, P., Jain, Dipak C. y Maesincee, Suvit (2002). El Marketing se mueve: una nueva aproximación a los beneficios, el crecimiento y la renovación. Barcelona: Paidós.

- LAMBIN, Jean-Jacques (1995). Marketing Estratégico. Madrid: McGraw-Hill, (primera versión en francés, publicada en 1989).

- LAZER, William y KELLY, Eugene J. (1962). "Systems Perspective of Marketing Activity”. En: Managerial Marketing: Perspectives and Viewpoints. Illinois: Richard D. Irwin, Inc., edición revisada. -LEVITT, T. (1960). "Marketing Myopia". En: Harvard Business Review, Vol. 38.

- LEVITT, T. (1969). La Moda del Marketing: Caminos para un crecimiento empresarial. New York: McGraw Hill.

- LILIEN, Gary y KOTLER, Philip (1990). Toma de Decisiones en Mercadotecnia: un enfoque a la construcción de modelos. México: Compañía Editorial Continental.

- LLINÁS, Rodolfo (2002). El Cerebro y el Mito del Yo: el papel de las neuronas en el pensamiento y el comportamiento humanos. Bogotá: Norma.

- McCARTHY, E. Jerome y PERREAULT, W. (1990). Basic Marketing: A Managerial Approach. Illinois: Richard Irwin Homewood, (1a. ed. de 1960).

- NARVER, J. y SLATER, S. (1990). “The Effect of a Marketing Orientation on Business Profitability”. En: Journal of Marketing, Vol. 54, pp. 20-35.

- PORTER, M. (1985). Estrategia Competitiva: Técnicas para el Análisis de Sectores Industriales y de la Competencia. Madrid: CECSA, (primera versión en inglés, publicada en 1980).

- PORTER, M. (1990). Ventaja Competitiva: creación y sostenimiento de un desempeño superior. Madrid: CECSA, (primera versión en inglés, publicada en 1985).

- PORTER, M. (1991). La Ventaja Competitiva de las Naciones. Madrid: Plaza y Janes.

- RIES, Al y TROUT, Jack (1990). Posicionamiento: El concepto que ha revolucionado la comunicación publicitaria y la mercadotecnia. Madrid: McGrawHill: (primera versión en inglés publicada en 1980).

- SAGAN, Carl (1995). El Mundo y sus Demonios: la ciencia como una luz en la oscuridad. Barcelona: Planeta.

- SARABIA, F. (1999). Metodología para la investigación en marketing y dirección de empresas. Madrid: Pirámide.

- SHETH, J., GARDNER, D. y GARRETT, D. (1988). Marketing Theory: evolution 
and evaluation. New York: John Wiley \& Son.

- SALLENAVE, J. P. (1995). La Teoría "L“de la Administración - La Antigestión. Bogotá: Norma.

- SCHWARTZ, George (1969). La Teoría del Marketing. Barcelona: Ed. Labor S.A.

- STANTON, William J.; Etzel, Michael J.; y Walker, Bruce J. (1992). Fundamentos de Marketing. México: McGraw-Hill, (novena edición).

- STIGLITZ, Joseph E. (2003). Los Felices 90: la semilla de la destrucción: Madrid: Taurus.

- WEBSTER, Frederick (Jr) (1981). "Top Management's Concerns about Marketing Issues for the 1980's". En: Journal of Marketing, Vol. 45, pp. 9-16.

- WEBSTER, Frederick (Jr) (1988). "The Rediscovery of the Marketing Concept”. En: Business Horizons, Vol. 31, pp. 9-16.

-WEBSTER, Frederick (Jr) (1992). “The Changing Role of Marketing in the Corporation". En: Journal of Marketing, Vol. 56, pp. 1-17.
- WEBSTER, Frederick E. (Jr) (1994). Market-Driven Management: Using the new marketing concept to create a customer-oriented company. New York: John Wiley \& Sons, Inc.

\section{NOTA FINAL}

Los puntos de vista que aquí se muestran han sido parte del material de trabajo de los cursos de Marketing Estratégico y Marketing Operativo que propuse, diseñé y comencé a enseñar, para los estudiantes del Postgrado de Psicología del Consumidor, de la Universidad Konrad Lorenz, desde 1995. Igualmente, han sido totalmente documentados en los diferentes lugares de trabajo, cursos, seminarios, capacitaciones, asesorías y consultorías, que he realizado para varias empresas, entidades, instituciones y universidades, desde igual año: Jorge Enrique Garcés Cano, "Visiones Dinámica, Sistémica y Funcional de la Planeación Estratégica de Mercadeo (PEM)", 1995-2004, D. R. A. (material sin publicar). 